\title{
Analisis Molekular dan Transpor Ion Amonium klorida
}

\author{
Gebby Rhaska ${ }^{1}$, Rahadian Zainul ${ }^{2}$ \\ ${ }^{1}$ Pendidikan Kimia, FMIPA, Universitas Negeri Padang, Indonesia \\ ${ }^{2}$ Physical Chemistry Laboratory, FMIPA, Universitas Negeri Padang, Indonesia \\ *E-mail : ${ }^{1}$ gebbyrhaska@yahoo.com \\ rahadianzainul@yahoo.com
}

\begin{abstract}
Abstrak. Ammonium Chlorida merupakan seanyawa anorganik dengan rumus kimia $\mathrm{NH}_{4} \mathrm{Cl}$, berupa garam Kristal puth yang sangat mudah larut dalam air.Ammonium Chlorida banyak digunakan pada bidang industry. Tujuan dari review ini untuk mengetahui karakteristik molekul dan transpor ion Ammonium Chlorida. Metode yang digunakan untuk mengetahui karakteristik molekul yaitu metode pemodelan komputasi di ChemOffice 15.0, dan untuk mengetahui transpor ion Ammonium Chlorida yaitu dengan parameter konduktivitas, viskositas, mobilitas ion, dan gerakan hanyut.Hasil yang didapat yaitu struktur molekul Ammonium Chlorida pada analisis molekuler 2D, dan bentuk molekul 3D. Ammonium klorida memiliki sifat termokimia dalam fasa solid dengan $\triangle S, C, \Delta H_{f}, \Delta G$ pada tekanan 1 atm pada suhu $25^{\circ} \mathrm{C}$ yang masing-masing memiliki nilai 94,56 $\mathrm{J} \mathrm{mol}^{-1} \mathrm{~K}^{-1}, 84,1 \mathrm{~J} \mathrm{~mol}^{-1} \mathrm{~K}^{-1},-314,43 \mathrm{kJmol}^{-1}$, dan $-202,97 \mathrm{kJmol}^{-1}$. Pada suhu yang $100^{\circ} \mathrm{C}$ dengan tekanan yang sama 1 atm $\Delta \mathrm{H}$ reaksi yang didapatkan bernilai positif sehingga reaksi pembentukan $\mathrm{NH}_{4} \mathrm{Cl}$ bersifat endotermis. Interaksi molekul yang terjadi pada ion $\mathrm{NH}_{4} \mathrm{Cl}$ dapat diperhatikan melalui beberapa parameter, diantaranya adalah konduktivitas, mobilitas, serta kecepatan hanyut ionnya. Konduktivitas dari $\mathrm{NH}_{4} \mathrm{Cl}$ dipengaruhi oleh konsentrasi, semakin banyak ion yang ada dalam larutan maka mobilitas ion yang juga berhubungan dengan kecepatan hanyut dalam larutan akan semakin berkurang sehingga nilai konduktivitas akan menurun. Mobilitas ion $\mathrm{NH}_{4}^{+}$yaitu $3,5 \times 10^{-8} \mathrm{~m}^{2} \mathrm{~s}^{-1} \mathrm{~V}^{-1}$, serta kecepatan hanyut $\mathrm{NH}_{4} \mathrm{Cl}$ sebesar 3,00 V/cm. Berdasrkan metoda komputasi dengan ChemOffice 3D, energy yang dibutuhkan $\mathrm{NH}_{4} \mathrm{Cl}$ untuk bergerak sebesar $14,87 \mathrm{kcal} / \mathrm{mol}$
\end{abstract}

Kata Kunci: Ammonium Chlorida, bentuk molekul, mobilitas ion, luas permukaan, konduktivitas.

\section{Pendahuluan}

Amonium klorida ${ }^{(22-29)}$ merupakan senyawa anorganik dengan rumus $\mathrm{NH}_{4} \mathrm{Cl}$, berupa garam kristal putih yang sangat mudah larut dalam air. Larutan amonium klorida bersifat asam lemah. Nama alami dari Ammonium Chlorida adalah Sal amoiak, bentuk mineral amonium klorida ${ }^{(23,26,27)}$. Mineral ini umum terbentuk pada pembakaran batu bara akibat kondensasi gas-gas yang dihasilkan.

Ammonium Chlorida digunakan sebagai bahan baku pembuatan batu baterai, pembersih solder yang digunakan untuk industry elektronika, obat batuk (expectorant), pengeras salju, pupuk, dan bahan reduksi nitroparaffin menjadi alkylhydroxylamine. Di Indonesia sendiri sangat membutuhkan Ammonium Chlorida dalam jumlah yang banyak, sekitar 7590,584 ton/tahun. Sampai saat ini Indonesia masih mengekspor kebutuhan $\mathrm{NH}_{4} \mathrm{Cl}$ dari luar negeri.

Selain ditemukan dialam, ammonium klorida bisa kita buat sendiri. Salah satunya dengan cara mencampurkan larutan ammonium hidroksida dengan larutan asam klorida. Saat dicampurkan kedua larutan ini akan terbentuk endapan putih. Endapan ini yang merupakan ammonium klorida. 
Ada empat macam proses pembuatan ${ }^{(203)}$ Ammonium Chlorida adalah proses ammoniumsoda, yang mana $\mathrm{NH}_{4} \mathrm{Cl}$ digunakan sebagai produk samping dari proses Solvay yang digunakan pada pembuatan $\mathrm{NaHCO}_{3}$. Reaksi yang terjadi yaitu :

$$
\mathrm{NaCl}+\mathrm{NH}_{3}+\mathrm{CO}_{2}+\mathrm{H}_{2} \mathrm{O} \longrightarrow \mathrm{NaHCO}_{3}+\mathrm{NH}_{4} \mathrm{Cl}
$$

Pada proses kedua yaitu, proses Amonium Sulfit-Sodium Klorida, pada proses ini akan terjadi bila bahan baku telah tersedia semua dan dalam kemurnian tinggi. Reaksi yang terjadi ;

$2 \mathrm{NaCl}+\mathrm{SO}_{2}+\mathrm{NH}_{3}+\mathrm{H}_{2} \mathrm{O} \longrightarrow \mathrm{NaSO}_{3}+\mathrm{NH}_{4} \mathrm{Cl}$

Pada proses selanjutnya, proses netralisasi Lansung, reaksi yang terjadi :

$\mathrm{NH}_{3}+\mathrm{HCl} \longrightarrow \mathrm{NH}_{4} \mathrm{Cl} \quad \Delta \mathrm{H}=-175,7 \mathrm{~kJ} / \mathrm{mol}$ 


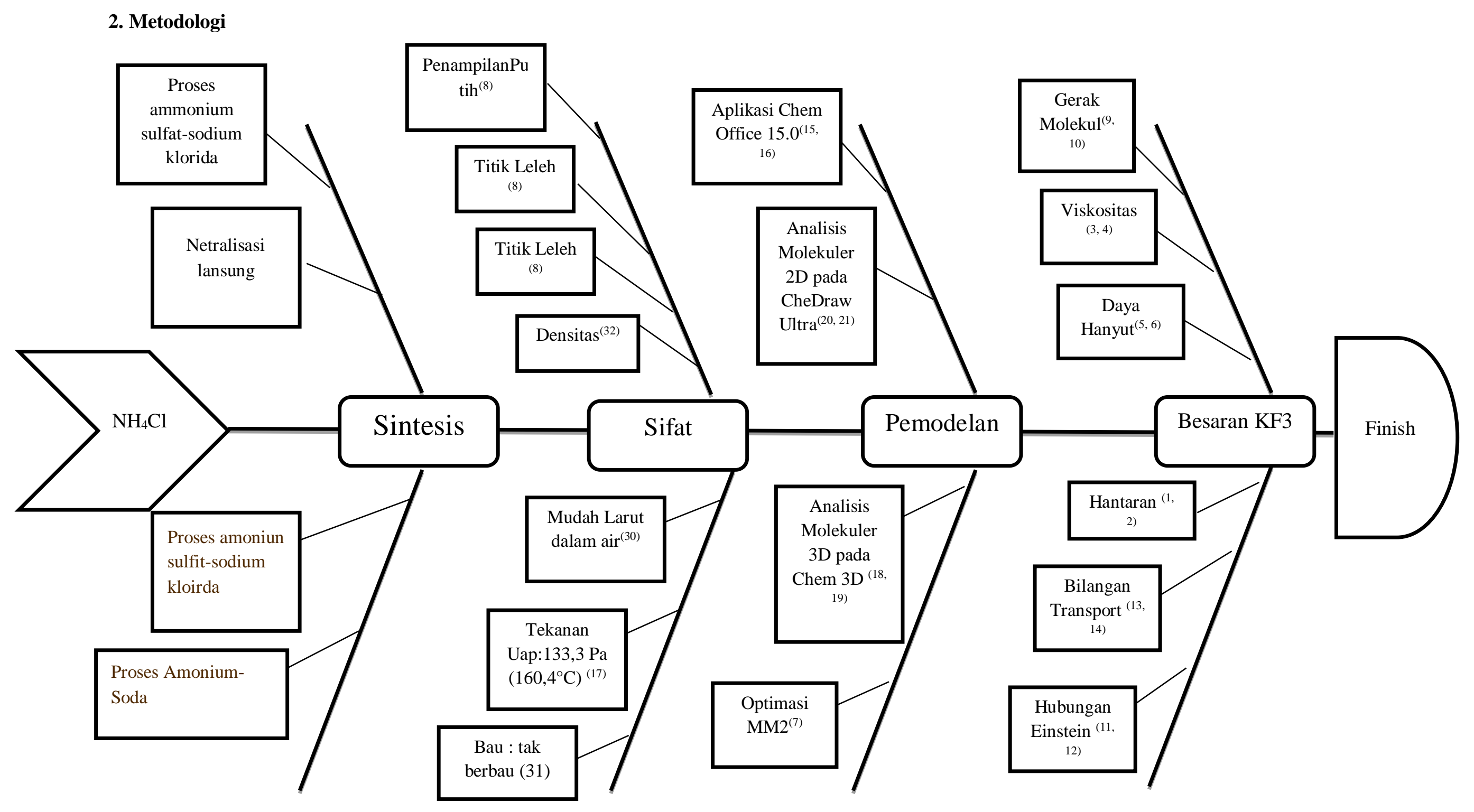


Review ini menggunakan pemodelan dengan menggunakan aplikasi (Software) Chem Office 2008 (ChemDraw Ultra versi 8 dan Chem3D versi 8), Penelitian ini memiliki tahapan, yaitu (1) Analisis molekul $\mathrm{NH}_{4} \mathrm{Cl}$ secara dua dimensi menggunakan ChemDraw Ultra; (2) Analisis molekul $\mathrm{NH}_{4} \mathrm{Cl}$ secara tiga dimensi menggunakan ChemDraw Ultra dam diproyeksikan pada Chem 3D. Pemodelan ini dengan mengasumsikan pada satu molekul $\mathrm{NH}_{4} \mathrm{Cl}$ dengan beberapa kemungkinan pergerakan dan vibrasional yang terjadi.

Molekul $\mathrm{NH}_{4} \mathrm{Cl}$ mulanya dilukis dengan menggunakan software dari ChemDraw Ultra dengan langkah, yakni klik structure, pilih bagian bawah " convert name to structure ", selanjutnya akan muncul pada layar kerja dan tulis "ammonium chloride", klik $\mathrm{OK}$, rumus molekul dari $\mathrm{NH}_{4} \mathrm{Cl}$ terbentuk. Langkah selanjutnya dalam analisis molekul tersebut, dilakukan pada bagian view dengan langkah, yaitu klik menu view, lalu pilih show analysis window dan show chemical properties windows, akan muncul kotak hasil dari analisis, pilih paste, maka akan secara otomatis tertulis pada layar kerja tersebut.

Pada analisis 3D dilakukan dengan mentransformasikan molekul 2D ke Chem3D. Pada bagian Chem3D, struktur $\mathrm{NH}_{4} \mathrm{Cl}$ berubah menjadi 3 dimensi dan menganalisis kondisi sebelum optimasi dengan pilihan select untuk ukuran yang diinginkan. Misalkan pada pengukuran antara atom, maka dapat dilakukan dengan meletakkan kursor pada bagian penghubung bentuk 3 dimensi dari molekul $\mathrm{KOH}$ tersebut, untuk calculation pada energy, molecular dynamics, compute properties maka dapat dilakukan dengan klik menu toolbar "MM2 “, untuk calculation charge dan surface dapat dilakukan dengan mengklik menu toolbar " Analyze " yang selanjutnya memilih optional Extended Huckel Charges dan Extended Huckel Surface.

\section{Analisis GAP}

Ammonium klorida digunakan sebagai sumber nitrogen dalam pupuk (sesuai dengan $90 \%$ dari produksi dunia ammonium klorida), misalnya Chloroammonium fosfat. Terdapat pada tanaman di Asia adalah padi dan gandum. Dalam dunia kesehatan ammonium klorida mempunyai manfaat untuk mengatasi rendahnya klorida dalam darah dan alkalosis metabolic. Ammonium klorida dapat bekerja dengan meningkatkan ion klorida dan meningkatkan ion hydrogen bebas dalam darah sehingga darah menjadi asam. Namun di Indonesia tidak bisa memanfaatkan ammonium klorida dalam bidang kesehatan

\section{Pembahasan}

\section{Result}

Tabel 1Sifat fisika dan kimia Ammonium Chlorida

\begin{tabular}{cc}
\hline & Karakteristik \\
\hline Nama Senyawa & Ammonium Klorida \\
Simbol & $\mathrm{NH}_{4} \mathrm{Cl}$ \\
Bau & Tak berbau \\
Penampilan & berwarna puth \\
Massa Molar & $53,49 \mathrm{~g} \cdot \mathrm{mol}^{-1}$ \\
Tekanan Uap & $133,3 \mathrm{~Pa}\left(160,4^{\circ} \mathrm{C}\right)$ \\
Densitas & $1,5274 \mathrm{~g} \mathrm{~cm}^{-3}$ \\
Kelarutan dalam air & $244 \mathrm{~g} / \mathrm{L}\left(-15^{\circ} \mathrm{C}\right)$ \\
Hasil kali kelarutan & $30,9(395 \mathrm{~g} / \mathrm{L})$ \\
Titik lebur & $538^{\circ} \mathrm{C} \mathrm{dekomposisi,} \mathrm{menyublim}$ \\
Titik didih & $520^{\circ} \mathrm{C}$ \\
Keasamaan (pKa) & 9,24 \\
Densitas & $1,5274 \mathrm{~g} \mathrm{~cm}^{-3}$ \\
\hline
\end{tabular}




\section{Data Molekul}

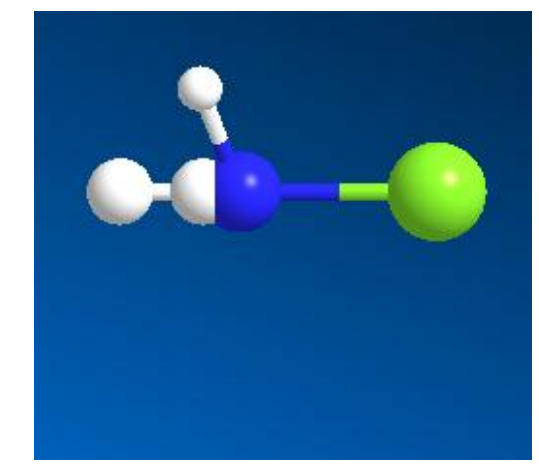

Gambar 1 Molekul ammonium klorida

MM2 Constant Value Quality

Cubic stretch constant-2.000 4

Quartic stretch constant2.333 4

X-B,C,N,O-H Stretch-Bend interaction force constant0.090 4

Sextic bending constant $(* 10 * * 8) 7.000 \quad 4$

Cutoff distance for charge/charge interactions $35.000 \quad 4$

Cutoff distance for charge/dipole interactions25.000 4

Cutoff distance for dipole/dipole interactions 18.000 4

Cutoff distance for van der Waals interactions $10.000 \quad 4$

$\begin{array}{lcccccc}\text { MM2 } & \text { c3dAtomRadius } & \text { Eps } & \text { Weight } & \text { Reduct } & \text { Lone Pairs Quality } \\ 39 & 1.820 & 0.055 & 14.003 & 0.000 & 0 & 3 \\ 170 & 2.280 & 0.300 & 34.969 & 0.000 & 0 & 3 \\ 48 & 0.900 & 0.015 & 1.008 & 0.000 & 0 & 3\end{array}$

Bond KS Bond Length Dipole Quality

$\begin{array}{lllll}39-48 & 6.100 & 1.045 & 0.000 & 2\end{array}$

Angle KB XR2 XRH XH2 Quality

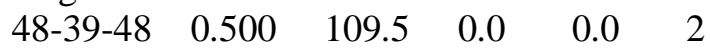

\section{Bentuk Molekul}

a) Analisis $2 \mathrm{D}$ pada molekul $\mathrm{NH}_{4} \mathrm{Cl}$

Molekul $\mathrm{NH}_{4} \mathrm{Cl}$ dibuat dengan menggunakan Chemdraw Ultra dihasilkan karakterisasi sebagai berikut:

$$
\mathrm{NH}_{4}{ }^{+} \mathrm{Cl}^{-}
$$

\section{ammonium chloride}

Gambar 2. Struktur ammonium klorida

$$
\mathrm{NH}_{4}^{+} \mathrm{Cl}^{-}
$$

ammonium chloride

Chemical Formula: $\mathrm{ClH}_{4} \mathrm{~N}$

Exact Mass: 53.00

Molecular Weight: 53.49

$\mathrm{m} / \mathrm{z}: 53.00(100.0 \%), 55.00(32.0 \%)$

Elemental Analysis: Cl, 66.28; H, 7.54; N, 26.19 


\section{b) Analisis 3D pada molekul $\mathrm{NH}_{4} \mathrm{Cl}$}

Molekul $\mathrm{NH}_{4} \mathrm{Cl}$ dibuat dengan menggunakan Chemdraw Ultra diproyeksikan pada Chem 3D untuk analisis 3 Dimensi.

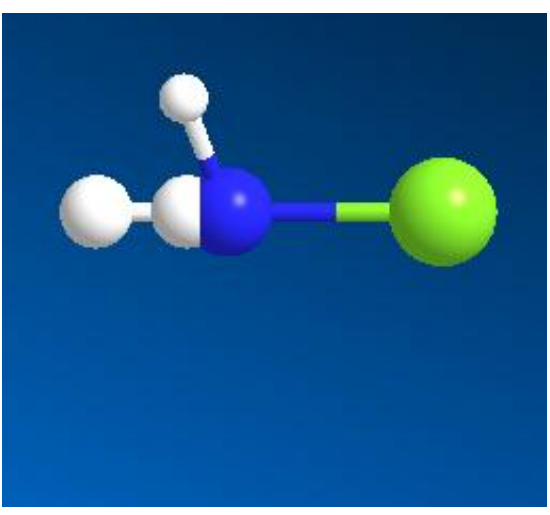

(a)

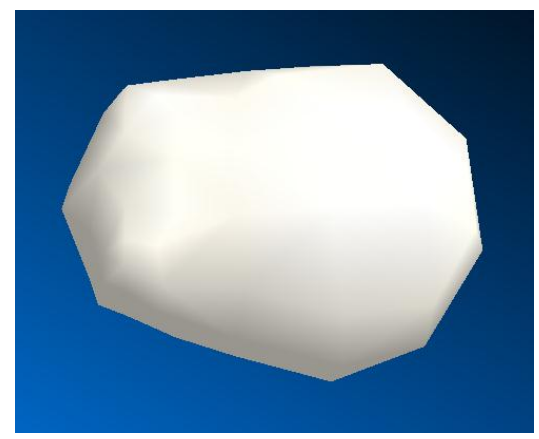

(b)

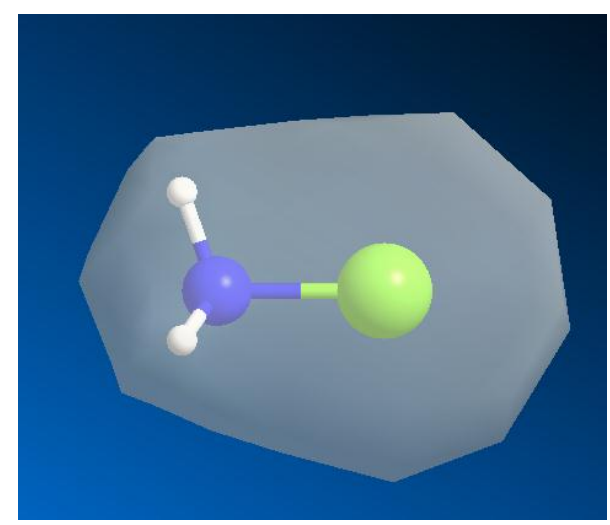

(e)

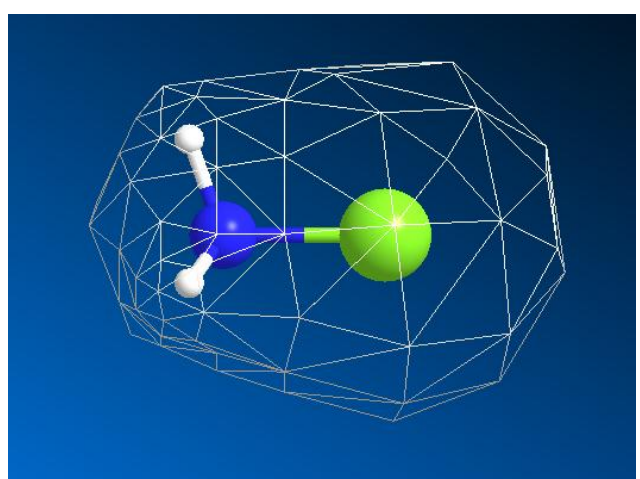

(c)

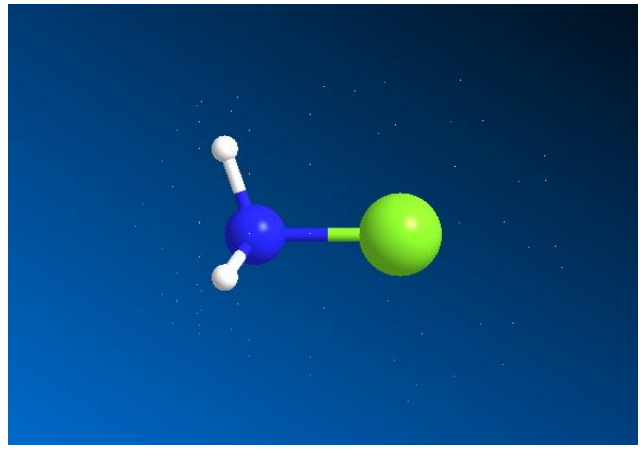

(d)

Gambar 2. (a) Bentuk-bentuk molekul $\mathrm{NH}_{4} \mathrm{Cl} 3 \mathrm{D}$

Analisis 3D surface $\mathrm{NH}_{4} \mathrm{Cl}$ (b)solid (c)wire Mesh (d)Dots (e)Solvent Accessible (ChemOffice 3D version 15, perkinelmer informatics. Inc,2015) 
3) Optimasi Molekul $\mathrm{Na}_{2} \mathrm{SiO}_{3}$ menggunakan Molecular Mechanic (MM2)

Optimasi molekul $\mathrm{NH}_{4} \mathrm{Cl}$ dilakukan dengan Molekular Mekanik (MM2) ${ }^{(212)}$ dan menghasilkan output data dalam bentuk data geometri ${ }^{(190)}$ atom atom dalam molekul dan Energi optimumnya ${ }^{(184)}$. Hasil output yang dioleh dapat dilihat sebagai berikut :
1. Optimasi MM2 Minimization
2. Optimasi MM2 Dynamics
3. Optimasi MM2 Properties

MM2 Calculation completed successfully

-MM2 Minimization-

Warning: The number of ligands attached does not match the geometry of $\mathrm{Cl}(2)$

Warning: Some parameters are guessed (Quality $=1$ ).

Iteration 1 Steric Energy 0.000 RMS Gradient 0.041 RMS Move 0.0000

Iteration 2 Steric Energy 0.000 RMS Gradient 0.055 RMS Move 0.0001

Iteration 3 Steric Energy 0.000 RMS Gradient 0.038 RMS Move 0.0001

Iteration 4 Steric Energy 0.000 RMS Gradient 0.013 RMS Move 0.0000

Iteration 5 Steric Energy 0.000 RMS Gradient 0.007 RMS Move 0.0000

Iteration 5: Minimization terminated normally because the gradient norm is less than the minimum gradient norm

$\begin{array}{lc}\text { Stretch: } & 0.0000 \\ \text { Bend: } & 0.0001 \\ \text { Stretch-Bend: } & -0.0000 \\ \text { Torsion: } & 0.0000 \\ \text { Non-1,4 VDW: } & 0.0000 \\ \text { 1,4 VDW: } & 0.0000 \\ \text { Charge/Charge: } & 0.0000 \\ \text { Total Energy: } & 0.0001 \mathrm{kcal} / \mathrm{mol} \\ \text { Calculation ended } & \end{array}$

MM2 Calculation completed successfully MM2 Dynamics

Warning: The number of ligands attached does not match the geometry of $\mathrm{Cl}(2)$

Warning: Some parameters are guessed $($ Quality $=1)$.

Iteration Time Total Energy Potential Energy Temperature

$\begin{array}{lllll}1 & 0.002 & 0.000 \pm 0.000 & 0.000 \pm 0.000 & 0.00 \pm 0.00 \\ 2 & 0.004 & 0.023 \pm 0.000 & 0.018 \pm 0.000 & 0.35 \pm 0.00 \\ 3 & 0.006 & 0.036 \pm 0.000 & 0.007 \pm 0.000 & 1.96 \pm 0.00 \\ 4 & 0.008 & 0.057 \pm 0.000 & 0.047 \pm 0.000 & 0.70 \pm 0.00 \\ 5 & 0.010 & 0.052 \pm 0.000 & 0.006 \pm 0.000 & 3.12 \pm 0.00 \\ 6 & 0.012 & 0.064 \pm 0.000 & 0.040 \pm 0.000 & 1.62 \pm 0.00 \\ 7 & 0.014 & 0.060 \pm 0.000 & 0.020 \pm 0.000 & 2.68 \pm 0.00 \\ 8 & 0.016 & 0.074 \pm 0.000 & 0.030 \pm 0.000 & 2.97 \pm 0.00 \\ 9 & 0.018 & 0.071 \pm 0.000 & 0.039 \pm 0.000 & 2.15 \pm 0.00 \\ 10 & 0.020 & 0.098 \pm 0.000 & 0.033 \pm 0.000 & 4.36 \pm 0.00 \\ 11 & 0.022 & 0.101 \pm 0.000 & 0.062 \pm 0.000 & 2.59 \pm 0.00 \\ 12 & 0.024 & 0.107 \pm 0.000 & 0.015 \pm 0.000 & 6.13 \pm 0.00 \\ 13 & 0.026 & 0.144 \pm 0.000 & 0.089 \pm 0.000 & 3.68 \pm 0.00 \\ 14 & 0.028 & 0.132 \pm 0.000 & 0.022 \pm 0.000 & 7.41 \pm 0.00 \\ 15 & 0.030 & 0.139 \pm 0.000 & 0.057 \pm 0.000 & 5.53 \pm 0.00 \\ 16 & 0.032 & 0.133 \pm 0.000 & 0.033 \pm 0.000 & 6.70 \pm 0.00 \\ 17 & 0.034 & 0.149 \pm 0.000 & 0.035 \pm 0.000 & 7.68 \pm 0.00 \\ 18 & 0.036 & 0.131 \pm 0.000 & 0.035 \pm 0.000 & 6.42 \pm 0.00 \\ 19 & 0.038 & 0.140 \pm 0.000 & 0.021 \pm 0.000 & 7.99 \pm 0.00 \\ 20 & 0.040 & 0.149 \pm 0.000 & 0.059 \pm 0.000 & 5.98 \pm 0.00 \\ 21 & 0.042 & 0.149 \pm 0.000 & 0.015 \pm 0.000 & 9.00 \pm 0.00\end{array}$




$\begin{array}{llllc}22 & 0.044 & 0.174 \pm 0.000 & 0.070 \pm 0.000 & 6.97 \pm 0.00 \\ 23 & 0.046 & 0.163 \pm 0.000 & 0.032 \pm 0.000 & 8.77 \pm 0.00 \\ 24 & 0.048 & 0.187 \pm 0.000 & 0.059 \pm 0.000 & 8.56 \pm 0.00 \\ 25 & 0.050 & 0.176 \pm 0.000 & 0.048 \pm 0.000 & 8.63 \pm 0.00 \\ 26 & 0.052 & 0.181 \pm 0.000 & 0.023 \pm 0.000 & 10.63 \pm 0.00 \\ 27 & 0.054 & 0.182 \pm 0.000 & 0.066 \pm 0.000 & 7.79 \pm 0.00 \\ 28 & 0.056 & 0.186 \pm 0.000 & 0.018 \pm 0.000 & 11.29 \pm 0.00 \\ 29 & 0.058 & 0.190 \pm 0.000 & 0.070 \pm 0.000 & 8.06 \pm 0.00 \\ 30 & 0.060 & 0.187 \pm 0.000 & 0.021 \pm 0.000 & 11.13 \pm 0.00 \\ 31 & 0.062 & 0.200 \pm 0.000 & 0.061 \pm 0.000 & 9.34 \pm 0.00 \\ 32 & 0.064 & 0.186 \pm 0.000 & 0.039 \pm 0.000 & 9.88 \pm 0.00 \\ 33 & 0.066 & 0.203 \pm 0.000 & 0.053 \pm 0.000 & 10.10 \pm 0.00 \\ 34 & 0.068 & 0.200 \pm 0.000 & 0.064 \pm 0.000 & 9.14 \pm 0.00 \\ 35 & 0.070 & 0.211 \pm 0.000 & 0.019 \pm 0.000 & 12.94 \pm 0.00 \\ 36 & 0.072 & 0.235 \pm 0.000 & 0.073 \pm 0.000 & 10.87 \pm 0.00 \\ 37 & 0.074 & 0.234 \pm 0.000 & 0.007 \pm 0.000 & 15.22 \pm 0.00 \\ 38 & 0.076 & 0.263 \pm 0.000 & 0.086 \pm 0.000 & 11.86 \pm 0.00 \\ 39 & 0.078 & 0.250 \pm 0.000 & 0.042 \pm 0.000 & 13.96 \pm 0.00 \\ 40 & 0.080 & 0.286 \pm 0.000 & 0.077 \pm 0.000 & 14.05 \pm 0.00 \\ 41 & 0.082 & 0.276 \pm 0.000 & 0.069 \pm 0.000 & 13.92 \pm 0.00 \\ 42 & 0.084 & 0.304 \pm 0.000 & 0.045 \pm 0.000 & 17.41 \pm 0.00 \\ 43 & 0.086 & 0.298 \pm 0.000 & 0.095 \pm 0.000 & 13.61 \pm 0.00 \\ 44 & 0.088 & 0.299 \pm 0.000 & 0.016 \pm 0.000 & 18.99 \pm 0.00 \\ 45 & 0.090 & 0.332 \pm 0.000 & 0.112 \pm 0.000 & 14.75 \pm 0.00 \\ 46 & 0.092 & 0.315 \pm 0.000 & 0.021 \pm 0.000 & 19.72 \pm 0.00 \\ 47 & 0.094 & 0.349 \pm 0.000 & 0.102 \pm 0.000 & 16.57 \pm 0.00 \\ 48 & 0.096 & 0.327 \pm 0.000 & 0.076 \pm 0.000 & 16.83 \pm 0.00 \\ 49 & 0.098 & 0.354 \pm 0.000 & 0.073 \pm 0.000 & 18.84 \pm 0.00 \\ 50 & 0.100 & 0.348 \pm 0.000 & 0.126 \pm 0.000 & 14.87 \pm 0.00\end{array}$

Dari hasil optimasi MM2 terhadap molekul, energy steric molekul $\mathrm{NH}_{4} \mathrm{Cl}$ adalah : 38.852 $\mathrm{kcal} / \mathrm{mole}$. Jarak antara atom $\mathrm{N}(1)-\mathrm{H}(3)$ adalah $1,005^{\circ} \mathrm{A}$, atom $\mathrm{N}(1)-\mathrm{H}(4)$ adalah $1.045^{\circ} \mathrm{A}$, atom $\mathrm{N}(1)-\mathrm{H}(5)$ adalah $1.100^{\circ} \mathrm{A}, \mathrm{N}(1)-\mathrm{Cl}(2)$ adalah $1.654^{\circ} \mathrm{A}$. Massa atom $\mathrm{N}$ adalah $14,00 \mathrm{gram} / \mathrm{mol}$, atom $\mathrm{H}$ adalah 1,0079 gram $/ \mathrm{mol}$, dan atom $\mathrm{Cl}$ adalah 35,453 gram $/ \mathrm{mol}$.

\section{Sumber}

Ammonium klorida dapat diproduksi dengan empat macam proses, yaitu :

\subsection{Proses Amoium-soda}

Ammonium klorida dibuat untuk produk samping dari proses solvay ${ }^{(176)}$ yang digunakan pada pembuatan Natrium Karbonat. Reaksi yang terjadi yaitu :

$\mathrm{NaCl}+\mathrm{NH}_{3} \longrightarrow \mathrm{NaHCO}_{3}+\mathrm{NH}_{4} \mathrm{Cl}$

Pada reaksi ini natrium bikarbonat mengendap dari larutan dan dapat dipisahkan secara filtrasi ${ }^{(177)}$.Proporsi ammonium klorida dapat bergantung pada permintaan pasar, hanya dibuat sesuai dengan permintaan.

\subsection{Proses Amonium Sulfit- Sodium klorida}

Proses ini dapat terjadi bila bahan baku tersedia semua dan dalam bentuk kemurnian tinggi. Reaksi yang terjadi sebagai berikut :

\section{$2 \mathrm{NaCl}+\mathrm{SO}_{2}+2 \mathrm{NH}_{3}+\mathrm{H}_{2} \mathrm{O} \longrightarrow \mathrm{Na}_{2} \mathrm{SO}_{3}+\mathrm{NH}_{4} \mathrm{Cl}$}

Pada proses ini terjadi pengendapan pertama kali adalah sodium sulfit, lalu dipindahkan dengan sentrifugasi, lalu dicuci, dan dikeringkan ${ }^{(183 / 0}$. Kemurnian dari produk yang didapatkan cukup tinggi.

\subsection{Proses Netralisasi Lansung}

Reaksi yang terjadi, yaitu :

$$
\mathrm{NH}_{3}+\mathrm{HCl} \longrightarrow \mathrm{NH}_{4} \mathrm{Cl} \quad \Delta \mathrm{H}=-175,7 \mathrm{~kJ} / \mathrm{mol}
$$


Reaksi berlansung secara eksotermik, dan panas yang dibangkitkan yang digunakan untuk menguapkan sebagian besar air, ada ketika asam klorida ${ }^{(33-37)}$ cair digunakan. Ammonium klorida ${ }^{(23,26 \text {, }}$ 27, 29) dapat dihasilkan lewat kristalisasi.

\subsection{Proses Amonium Sulfat-Sodium Klorida}

Pada proses ini dilakukan dengan cara mereaksikan larutan ammonium sulfat dengan menggunakan natriumklorida dalam reactor berpengaduk dan dijaga pada suhu $100^{\circ} \mathrm{C}$. Konversi reaksi dalam reactor sebesar $95 \%{ }^{(181)}$.

$\left(\mathrm{NH}_{4}\right)_{2} \mathrm{SO}_{4}+2 \mathrm{NaCl} \longrightarrow 2 \mathrm{NH}_{4} \mathrm{Cl}+\mathrm{Na}_{2} \mathrm{SO}_{4}$

\section{Karakter Atom Penyusun dari Senyawa $\mathrm{NH}_{4} \mathrm{Cl}$ 5.1 Nitrogen $N$}

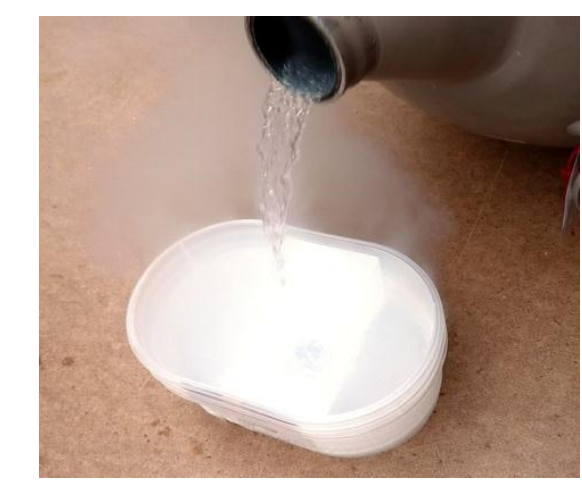

Gambar 3. Bentuk atom Nitrogen

Nitrogen ${ }^{(38)}$ merupakan suatu unsur kimia pada tabel periodik memilik lambang $\mathbf{N}$ dengan nomor atom 7. Nitrogen salah satu anggota paling ringan dari golongan $\mathrm{V}$ pada tabel periodik, yang seringkali disebut dengan "Pniktogen". Di alam semesta Nitrogen berada pada urutan ke-7 dari total kelimpahannya didalam galaksi bima sakti dan tata surya. Pada suhu dan tekanan standar atom nitrogen membentuk dua atom dengan unsur yang sama membentuk dinitrogen, yang merupakan suatu gas diatomik ${ }^{(39-41)}$ yang tak berwarna dan tak berbau dengan rumus kimia $\mathrm{N}_{2}$. Dinitrogen membentuk sekitar 78\% atmosfer bumi, membuatnya sebagai unsur mandiri yang paling melimpah.

Banyak senyawa yang paling penting pada bidang industry, seperti amonia ${ }^{(42-46)}$, asam nitrat $^{(47)}$, nitrat organik (propelan dan bahan peledak), serta sianida, mengandung nitrogen. Nitrogen banyak ditemukan dalam bentuk ikatan rangkap dua dan tiga, namun ada juga yang membentuk ikatan tunggal(single bond) ${ }^{(48-53)}$. Ikatan rangkap tiga pada atom nitrogen sangat kuat jika dibandingkan dengan ikatan tunggal dan ikatan rangkap dua. Hal ini menyebabkan kesulitan untuk baik organisme maupun bidang industry dalam mengubah $\mathrm{N}_{2}$ menjadi senyawa yang bermanfaat ${ }^{(223)}$. Sintesis amonia dan nitrat adalah pupuk industry utama, dan pupuk nitrat ${ }^{(54-61)}$ merupakan polutan utama dalam eutrofikasi sistem air.

Berikut sifat-sifat fisika dan kimia dari unsure nitrogen ;

Tabel 2. Sifat Fisika dan Kimia Nitrogen

\begin{tabular}{cc}
\hline & Karakteristik \\
\hline Nama & Nitrogen, \\
Simbol & $\mathrm{N}$ \\
Bau & Tak berbau \\
Penampilan & Tak berwarna, gas, cairan \\
Nomor atom & 7 \\
Kategori unsur & Non logam \\
Konfigurasi elektron & {$[\mathrm{He}] 2 \mathrm{~s}^{2} 2 \mathrm{p}^{3}$} \\
Fase & $\mathrm{Gas}$ \\
Titik lebur & $63,15 \mathrm{~K}$ \\
Titik didih & $77,36 \mathrm{~K}$ \\
Jari-jari kovalen & $71 \mathrm{pm}$ \\
Jari-jari Van Der Waals & $155 \mathrm{pm}$ \\
\hline
\end{tabular}




\subsection{Hidrogen $\mathrm{H}$}

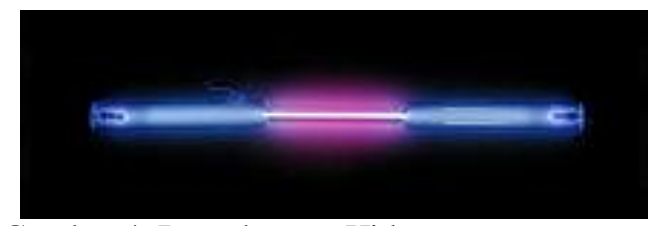

Gambar 4. Bentuk atom Hidrogen

Hidrogen dalam bahasa latin hydrogenium, dari bahasa Yunani hydro: air, genes: membentuk. Hidrogen ${ }^{(62-66)}$ merupakan salah satu unsur kimia dalam tabel periodik memilik simbol $\mathrm{H}$ dengan nomor atom 1. Pada suhu dan tekanan standar, hidrogen tak berwarna, tidak berbau, bersifat non logam, bervalensi tunggal dan merupakan gas diatomik yang sangat mudah terbakar.

Di alam, unsur hidrogen merupakan unsur yang paling melimpah dengan presentasi $\pm 75 \%$. Senyawa hidrogen biasanya dihasilkan secara industry dari berbagai senyawa hidrogen, seperti metana $^{(33-37,67-73)}$. Unsur hidrogen dapat dihasilkan dari air melalui proses elektrolisis ${ }^{(74-76)}$.

Tabel 3. Sifat Fisika dan Kimia Hidrogen

\begin{tabular}{cc}
\hline & Karakteristik \\
Nama & Hydrogen \\
Simbol & $\mathrm{H}$ \\
Bau & Tak berbau \\
Penampilan & Tak berwarna, gas \\
Nomor atom & 1 \\
Kategori unsur & Non logam \\
Konfigurasi elektron & $1 \mathrm{~s}^{1}$ \\
Fase & Gas \\
Titik lebur & $13,99 \mathrm{~K}$ \\
Titik didih & $20,271 \mathrm{~K}$ \\
Jari-jari kovalen & $37 \mathrm{pm}$ \\
Jari-jari Van Der Waals & $120 \mathrm{pm}$ \\
\hline
\end{tabular}

\subsection{Klorin $\mathrm{Cl}$}

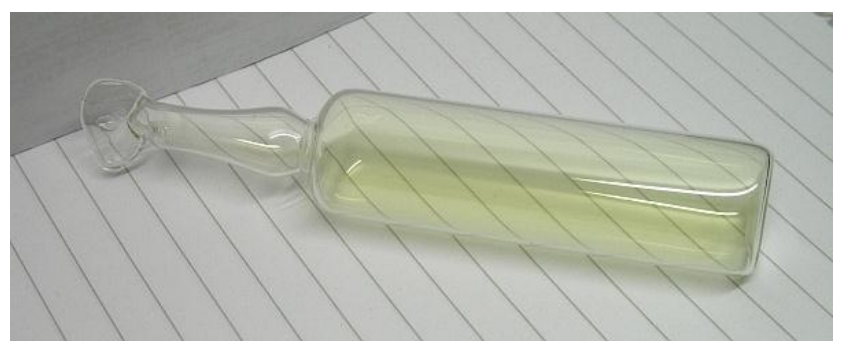

Gambar 5. Bentuk atom Klorin

Klorin ${ }^{(77,78)}$ merupakan salah satu unsur kimia dengan simbol $\mathrm{Cl}$ dengan nomor atom 17. Senyawa ini berada digolongan halogen ${ }^{(79-83)}$, senyawa yang paling ringan kedua berada diantara fluor dan bromin. Klorin berwujud gas yang berwarna kuning-hijau pada suhu kamar. Klor merupakan elemen sangat reaktif dan oksidator kuat, mempunyai afinitas elektron ${ }^{(84-89)}$, tertinggi dan elektronegativitas $^{(84-87)}$ tinggi ke-3 setelah oksigen ${ }^{(90-97)}$ dan fluor. 
Dalam bentuk ion klorida, klorin diperlukan untuk semua spesies hidup. Jenis senyawa klorin yang jarang ditemukan dalam organisme hidup, dan senyawa organik lain yang mengandung klor yang dibuat dari yang inert sampai beracun. Di atas atmosfer, molekul organik yang mengandung klorin seperti klorofluorokarbon ${ }^{(98-103)}$ yang telah mengakibatkan penipisan ozon.

Tabel 4. Sifat Fisika dan Kimia Klorin

\begin{tabular}{cc}
\hline & Karakteristik \\
\hline Nama & Klor \\
Bimbol & $\mathrm{Cl}$ \\
Penampilan & Tak berbau \\
Nomor atom & Berwarna hijau-kekuningan \\
Kategori unsur & 17 \\
Konfigurasi elektron & Halogen \\
Fase & {$[\mathrm{Ne}] 3 \mathrm{~s}^{2} 3 \mathrm{p}^{5}$} \\
Titik lebur & $\mathrm{Gas}$ \\
Titik didih & $171,6 \mathrm{~K}$ \\
Jari-jari kovalen & $239,11 \mathrm{~K}$ \\
Jari-jari Van Der Waals & $99 \mathrm{pm}$ \\
\end{tabular}

\section{Jari-jari Molekul}

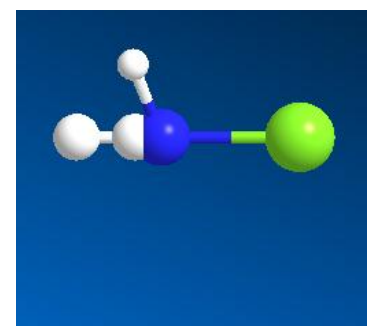

Gambar 6. Jarak antar atom pada molekul $\mathrm{NH}_{4} \mathrm{Cl}$

Jarak antara atom $\mathrm{N}(1)-\mathrm{H}(3)$ adalah $1,055^{\circ} \mathrm{A}$, atom $\mathrm{N}(1)-\mathrm{H}(4)$ adalah $1.045^{\circ} \mathrm{A}$, atom $\mathrm{N}(1)$ $\mathrm{H}(5)$ adalah $1.045^{\circ} \mathrm{A}, \mathrm{N}(1)-\mathrm{Cl}(2)$ adalah $1.666^{\circ} \mathrm{A}$. Massa atom ${ }^{(104-107)} \mathrm{N}$ adalah 14,00 gram $/ \mathrm{mol}$, atom $\mathrm{H}$ adalah $1,0079 \mathrm{gram} / \mathrm{mol}$, dan atom $\mathrm{Cl}$ adalah $35,453 \mathrm{gram} / \mathrm{mol}$.

Tabel 5. Jarak antar atom pada molekul $\mathrm{NH}_{4} \mathrm{Cl}^{(198)}$

\begin{tabular}{ccc}
\hline Atom & Bond Atom & Bond Length $(\AA)$ \\
\hline $\mathrm{Cl}(2)$ & $\mathrm{N}(1)$ & 1.666 \\
$\mathrm{H}(3)$ & $\mathrm{N}(1)$ & 1.045 \\
$\mathrm{H}(4)$ & $\mathrm{N}(1)$ & 1.045 \\
$\mathrm{H}(5)$ & $\mathrm{N}(1)$ & 1.045 \\
\hline
\end{tabular}

\section{Tinjauan Termodinamika}

Pada tinjauan termodinamika ${ }^{(178)}$ adalah suatu tinjauan yang bertujuan untuk mengetahui reaksi itu dibutuhkan panas atau melepaskan panas ${ }^{(210)}$. Secara termodinamika reaksi pembentukan ammonium klorida dapat dilihat dari nilai entalphi ${ }^{(179)}$ dan konstanta kesetimbangan $^{(191)}$.

Berikut sifat-sifat termodinamika ammonium klorida :

Tabel 6. Sifat Termokimia

\begin{tabular}{cc}
\hline \multicolumn{2}{c}{ Sifat-sifat Termodinamika } \\
\hline Kapasitas Kalor $(\mathrm{C})$ & $84,1 \mathrm{~J} \mathrm{~mol}^{-1} \mathrm{~K}^{-1}$ \\
Entropi Molar standar $(\Delta \mathrm{S})$ & $94,56 \mathrm{~J} \mathrm{~mol}^{-1} \mathrm{~K}^{-1}$
\end{tabular}


Pengaplikasian termodinamika ammonium klorida yang dilakukan pada suhu $25^{\circ} \mathrm{C}$ $\Delta \mathrm{Hf} \mathrm{NH} 4 \mathrm{C}$ $=-71,20 \mathrm{kkal} / \mathrm{mol}$

$\Delta \mathrm{Hf} \mathrm{NaSO} 4$

$$
=-330,82 \mathrm{kkal} / \mathrm{mol}
$$

$\Delta \mathrm{Hf}(\mathrm{NH} 4) 2 \mathrm{SO} 4$

$$
=-279,33 \mathrm{kkal} / \mathrm{mol}
$$

$\Delta \mathrm{Hf} \mathrm{NaCl}$

$$
=-97,324 \mathrm{kkal} / \mathrm{mol}
$$

Diketahui pada suhu $25^{\circ} \mathrm{C}=298 \mathrm{~K}$

$\Delta \operatorname{Hr} 298=\Sigma \Delta$ Hproduk $-\Sigma \Delta$ Hreaktan

$$
\begin{aligned}
& =(2 \Delta \mathrm{Hf} \mathrm{NH} 4 \mathrm{Cl}+\Delta \mathrm{Hf} \mathrm{Na} 2 \mathrm{SO} 4)-(\Delta \mathrm{Hf}(\mathrm{NH} 4) 2 \mathrm{SO} 4+2 \Delta \mathrm{Hf} \mathrm{NaCl}) \\
& =\{[2 \times(-71,20)]+(-330,82)-(-279,33)+[2 \times(-97,324)]\} \\
& =0,758 \mathrm{kkal} / \mathrm{mol}
\end{aligned}
$$

$$
\begin{aligned}
& \multicolumn{2}{c}{\text { Diketahui suhu } 100^{\circ} \mathrm{C}=373 \mathrm{~K}} \\
& \mathrm{Cp} \mathrm{NH}_{4} \mathrm{Cl}=23,53 \mathrm{kkal} / \mathrm{mol} \\
& \mathrm{Cp} \mathrm{Na}_{2} \mathrm{SO}_{4}=51,6 \mathrm{kkal} / \mathrm{mol} \\
& \mathrm{Cp} \mathrm{NaCl}=12,36 \mathrm{kkal} / \mathrm{mol} \\
& \Delta \mathrm{Hreaktan} 373=\Sigma \mathrm{Cp} \times \Delta \mathrm{T} \\
&=51,6 \times(373-298)+2 \times 12,36(373-298) \\
&=5,724 \mathrm{kkal} / \mathrm{mol} \\
& \Delta \text { Hproduk373 }=\Sigma \mathrm{Cp} \times \Delta \mathrm{T} \\
&=32,8 \times(373-298)+2 \times 23,53(373-298) \\
&=5.989,5 \mathrm{kkal} / \mathrm{mol}
\end{aligned}
$$

$\Delta$ Hreaksi $_{373}=\Delta$ Hproduk $_{373}+\Delta \mathrm{Hr}_{298}-\Delta$ Hreaktan $_{373}$

$$
\begin{aligned}
& =5.989,5+758-5.724 \\
& =1.023,5 \mathrm{kkal} / \mathrm{mol}
\end{aligned}
$$

Jadi $\Delta$ Hreaksi ${ }_{373}$ bernilai positif sehingga reaksi pembentukan ammonium klorida bersifat endotermis $^{(108,109)}$

\section{Gerak Molekul}

Untuk mengetahui bagaimana kekuatan hantaran dari molekul ammonium klorida ${ }^{(196)}$, terlebih dahulu mengetahui bagaimana pergerakan ion dari kation dan anion yang menyusun senyawa. Yang berperan sebagai kation dan anion ${ }^{(193)}$ dalam senyawa ini adalah kation disini yaitu $\mathrm{NH}_{4}{ }^{+}$dan anionnya yaitu $\mathrm{Cl}^{-}$. Setiap ion mempunyai laju ${ }^{(186)}$ yang berbeda-berbeda. Penyebab ion bergerak $^{(194)}$ inilah memiliki konduktivitas molar yang berbeda, serta sebab konduktivitas molar ${ }^{(213)}$ elektrolit kuat berkurang dengan akar konsentrasi.

Faktor-faktor yang mempengaruhi kecepatan ion : 
1. Berat dan muatan ion ${ }^{(197)}$, semakin ringan ion tiap satuan muatan maka semakin cepat ion bergerak

2. Adanya hidrasi ${ }^{(224)}$, semakin banyak molekul air yang mengerumuni ion maka semakin lambat gerakan ion

3. Orientasi atmosfer ${ }^{(100)}$ pelarut disekitar ion

4. Gaya tarik antara ion ${ }^{(225)}$, semakin besar gaya tarik maka semakin lambat gerakan ion

5. Temperatur, semakin tinggi temperatur maka semakin cepat gerakan ion (226).

6. Viskositas, semakin besar viskositas maka semakin lambat gerakan ion ${ }^{(227)}$.

Harga mobilitas ion mempengaruhi nilai konduktivitas dari suatu senyawa, semakin besar tingkat mobilitas ion dalam larutan maka semakin besar pula pengaruhnya konduktivitas ion dalam hal ini konduktivitas ion dalam senyawa ammonium klorida ${ }^{(204)}$

\section{Viskositas}

Viskositas gas sempurna

Kita sudah melihat bahwa viskositas berhubungan dengan fluks momentum ${ }^{(185)}$. Molekul yang berjalan dari kanan, mentransportasikan momentum ${ }^{(110-114)} m v_{x}(\lambda)$ kelapisan yang barupada $\mathrm{z}=0$, dan molekul yang berjalan dari kiri mentransportasikan $m v_{x}(-\lambda)$ kelapisan baru itu. Jika kita mengasumsikan bahwa rapataannya seragam (suatu pendekatan), maka jumlah benturan per satuan luar per satuan waktu pada jendela bayangan adalah $\frac{1}{4} \mathcal{N} c$. Molekulnya dari kanan, secara rata-rata membawa momentum ${ }^{(231)}$ :

$m v_{x}(\lambda)=m v_{x}(0)+m \lambda\left(\frac{d v_{x}}{d z}\right)_{0}$

Molekul dari kiri, membawa momentum :

$m v_{x}(-\lambda)=m v_{x}(0)-m \lambda\left(\frac{d v_{x}}{d z}\right)_{0}$

Jadi, fluks neto momentum $-\mathrm{x}$ dalam arah $\mathrm{z}$ adalah :

$$
\begin{aligned}
& J_{z}=\frac{1}{4} \mathcal{N} c\left\{\left[m v_{x}(0)-m \lambda\left(\frac{d v_{x}}{d z}\right)_{0}\right]-\left[m v_{x}(0)+m \lambda\left(\frac{d v_{x}}{d z}\right)_{0}\right]\right\} \\
& =-\frac{1}{2} \mathcal{N} m \lambda \bar{c}\left(\frac{d v_{x}}{d z}\right)_{0}
\end{aligned}
$$

Kita melihat bahwa fluks itu sebanding dengan gradient velositas ${ }^{(215-217)}$, seperti yang ingin kita buktikan. Maka kita dapat menunjukkan viskositas dengan

$\eta=\frac{1}{3} \mathcal{N} m \lambda \bar{c}=\frac{1}{3} \mathcal{N} m \lambda \bar{c} \mathcal{N}_{a}[A]$

Seperti juga konduktivitas termal ${ }^{(187)}$, viskositas tidak tergantung pada tekanan ${ }^{(205)}$. Jadi $\lambda \propto$ $1 / p$ dan $[A] \propto p$, menunjukkan bahwa $\eta \propto \bar{c}$ tidak yang mentransportasikan momentum ${ }^{(199)}$, tetapi pengangkutan itu tidak begitu jauh karena lebih pendeknya jalan bebas rata-rata ${ }^{(232)}$. Karena $\bar{c} \propto T^{1 / 2}$, maka viskositas sebanding dengan $T^{1 / 2}$. Jadi, viskositas gas bertambah dengan naiknya temperatur: molekul berjalan lebih cepat, dan fluks momentum lebih besar ${ }^{(233)}$.

\section{Kecepatan hanyut}

Jika dua elektroda yang terpisah dengan jarak ı berada pada selisih potensial $\Delta \phi$, maka ion dalam larutan di antara kedua elektroda itu, mengalami medan listrik seragam ${ }^{(192)}$,yaitu:

$$
\boldsymbol{E}=\frac{\Delta \phi}{i}
$$

Dalam medan demikian,ion yang bermuatan ${ }^{2} z e$ mengalami gaya sebesar :

$$
I e=z e E \frac{z e \Delta \phi}{i}
$$

Kation bereaksi dengan percepatan menuju elektroda negative dan anion bereaksi dengan percepatan menuju elektroda positif ${ }^{(228-230)}$ akan tetapi,saat ion bergerak melalui pelarut maka ion akan 
mengalami gaya gesekan $^{(214)}$ memperlambat Ie' yang sebanding dengan kecepatannya.dan jika diasumsikan bahwa hukum Stokes ${ }^{(115-118)}$ untuk bola radius a dan $s$ berlaku pada skala mikroskopis ,maka kita dapat menuliskan gaya perlambatan ini sebagai:

$$
\mathrm{Ie}=f_{s} f=6 \pi \eta a
$$

Kedua gaya itu bekerja dalam arah yang berlawanan,dan ion mencapai kecepatan akhir,yaitu kecepatan hanyut $^{(205)}$, jika gaya mempercepat Ie diimbangi oleh penahan kental Ie' gaya neto menjadi nol (Ie = Ie'), jika ;

$$
s=\frac{z e E}{f}
$$

karena kecepatan hanyut mengatur laju transportasi ion $^{(119-127)}$,maka dapat mengharapkan konduktivitas akan berkurang dengan bertambahnya viskositas pelarut akan ukuran ion ${ }^{(233,234)}$. Contohnya, konduktivitas molar ion logam alkali bertambah dari $\mathrm{Li}^{+} \mathrm{ke}^{+} \mathrm{Cs}^{+}$, walaupun radius ionnya bertambah, paradoks ini terpecahkan jika kita menyadari bahwa radius $a$ dalam rumus stokes adalah radius hidrodinamik ${ }^{(128,129)}$ ion, yaitu radius efektifnya dalam larutan dengan memperhitungkan molekul $\mathrm{H}_{2} \mathrm{O}$ yang dibawa dalam bola hidrasinya.ion kecil ${ }^{(180)}$ menimbulkan medan listrik lebih kuat dari pada ion besar sehingga ion kecil lebih terlarut secara ekstensif dari ion besar.jadi,ion dengan radius kecil dapat mempunyai radius hidrodinamik besar ${ }^{(200)}$,karena ion itu menyeret banyak molekul pelarut melalui larutan itu,saat bermigrasi ${ }^{(207)}$.

Didalam konduktor-konduktor gas,cairan,atau padat,partikel ${ }^{(201)}$ satu dengan partikel lainnya bertumbukan secara berulang-ulang yang menyebabkan kehilangan energi dan perubahan gerak secara $\operatorname{acak}^{(208)}$. Untuk menahan partikel bermuatan agar kecepatan rata-rata tetap digunakan kecepatan hanyut. Kecepatan hanyut mempunyai arah sama dengan medan listrik ${ }^{(202)}$ dan hubungan keduanya dinyatakan dalam suatu konstanta yang disebut dengan mobilitas ${ }^{(218)}$.

Gaya yang disebabkan oleh medan listrik $^{(130-138)}$.

$$
\mathbf{F}=\text { Ze. } \mathbf{E}
$$

Gaya tersebut dipengaruhi juga oleh gaya Viskos (kekentalan) yang dirumuskan oleh persamaan Stokes ${ }^{(235)}$ :

$$
\mathrm{F}=6 \pi \eta r v
$$

Dimana:

$$
\begin{array}{ll}
\eta: \text { viskositas } & v: \text { kecepatan } \\
r: \text { jari-jari } & Z e: \text { muatan masing-masing ion }
\end{array}
$$

Jika diabaikan efek penghambat lain, maka laju maksimum:

$$
v=\frac{Z e . E}{6 \pi \eta r v}=\mu . E
$$

Dimana: : mobilitas ion (koefisien perbandingan antara laju dan kuat medan).

Menurut persamaan (7), kecepatan hanyut ion sebanding dengan kuat medan yang diberikan. Jadi,kita menuliskan:

$$
\mathrm{S}=\boldsymbol{u E}
$$

Dimana $: u=$ koefisien perbandingan, dan disebut juga dengan mobilitas ion ${ }^{(139,140)}$ 
Perhitungan kecepatan hanyut :

Pemisalan Jika potensial $\mathrm{NH}_{4} \mathrm{Cl}$ 4,5 $\mathrm{V}$ dan jarak antara elektroda adalah 1,5 cm, maka kecepatan hanyutnya dapat dihitung sebagai berikut :

$$
\begin{aligned}
& E=\frac{\Delta \emptyset}{l} \\
& E=\frac{4.5 \mathrm{~V}}{1,5 \mathrm{~cm}}=3,00 \mathrm{~V} / \mathrm{cm}
\end{aligned}
$$

Jadi kecepatan hanyut $\mathrm{NH}_{4} \mathrm{Cl}$ adalah $3,00 \mathrm{~V} / \mathrm{cm}$

\section{Hantaran}

Kondutivitas atau hantaran ${ }^{(119-127,141-148)}$ merupakan pengukuran dasar untuk mempelajari gerakan ion ${ }^{(149-152)}$, konduktivitas atau daya hantar listrik adalah kekuatan seberapa kuat larutan dapat menghantarkan listrik ${ }^{(188)}$. Hantaran merupakan kebalikan dari hambatan listrik $^{(195)}$. Konduktivitas dapat diukur dengan alat Konduktometer. Prinsip kerja alat ini dengan mengukur perbandingan aliran listrik yang melalui sel terhadap voltase yang diberikan.

\section{Besaran KF3}

\section{Bilangan transport}

Bilangan transport ${ }^{(155-159)} \mathrm{t}$ didefinisikan sebagai fraksi dari arus total yang dibawa oleh ion jenis tertentu. Untuk larutan dengan dua jenis ion ${ }^{(189)}$, bilangan dengan $\mathrm{I}^{+}$merupakan arus yang dibawa oleh kation dan I adalah arus totalyang melalui larutan.bilangan transport anion I didefinisikan secara analog dalam $\mathrm{I}^{-}$, arus anion ${ }^{(219)}$. Karena arus total I merupakan jumlah dari arus kation dan aniom, maka:

$$
\mathbf{I}^{+}+\mathbf{I}^{-}=\mathbf{1}
$$

Bilangan transport pembatas $\mathrm{t}^{0}$ didefinisikan sama, tetapi untuk limit konsentrasi nol dari larutan eletrolit ${ }^{(160-168)}$ itu. Untuk selanjutnya, kita hanya akan memperhatikan nilai pembatas ini, agar terhindar dari masalah antaraksi ion ${ }^{(155,156,169,170)}$.

2) Hubungan Einstein

Hukum Fick untuk fluks partikel dalam mol molekul per satuan luas per satuan waktu ${ }^{(236)}$ adalah:

$$
\mathrm{J}=-\mathrm{D} \frac{d c}{d x}
$$

Dengan D merupakan koefisien difusi dan $d c / d x$ merupakan kemiringan dari konsentrasi molar. Fluks partikel ${ }^{(171-175)}$ berhubungan dengan kecepatan hanyut, dengan:

$$
J=s c
$$

Hubungan ini merupakan kelanjutan dari argument yang sudah kita gunakan beberapa kali sebelumnya. Jadi, semua partikel dalam jarak $s \Delta_{\mathrm{t}} A$, dapat melewati jendela dengan luas $A$ dalam selang waktu $\Delta_{\mathrm{t}}^{(220)}$. Dengan demikian, jumlah moldapat lewat dalam selang waktu itu adalah: $s \Delta_{\mathrm{t}} \mathrm{X} c$, sehingga:

$$
S c=-\mathrm{D} \frac{d c}{d x}
$$

Jika sekarang kita menyatakan $d c / d x$ dalam $f$, menggunakan persamaan 15 , maka kita memperoleh:

$$
S=-\frac{D}{c} \frac{d c}{d x}=\frac{D}{R T} \times \mathbf{f}
$$


Terdapat satu kasus ketika kita sudah mengetahui kecepatan hanyut dan gaya efektif ${ }^{(221)}$ yang bekerja pada partikel: ion dalam larutan mempunyai kecepatan hanyut $s=\mu E^{(237)}$ jika ion itu mengalami gaya $\mathrm{e} z E$, dan $z F E$ per mol, dari medan listrik dengan kuat medan $\mathrm{E}^{(238)}$. Jadi penggantian nilai tersebut ke dalam persamaan diatas, menghasilkan:

$$
\mu E=\frac{D}{R T} \times{ }_{Z} F E \text { atau } \mu=\frac{Z F D}{R T}
$$

Persamaan ini tertata ulang menjadi hasil yang sangat penting, yang dikenal sebagai hubungan Einstein $^{(211)}$, antara koefisien difusi dengan mobilitas ion:

$$
D=\frac{\mu R T}{{ }^{F} F}
$$

\section{Energi Stability}

Energi stabilitas ${ }^{(222)}$ yaitu energi dalam keadaan termodinamika pada suatu molekul yang mengalami kesetimbangan kimia dengan lingkungannya.

MM2 Calculation completed successfully

MM2 Dynamics

Warning: The number of ligands attached does not match the geometry of $\mathrm{Cl}(2)$

Warning: Some parameters are guessed (Quality $=1$ ).

Iteration Time Total Energy Potential Energy Temperature

$\begin{array}{lllll}1 & 0.002 & 0.000 \pm 0.000 & 0.000 \pm 0.000 & 0.00 \pm 0.00 \\ 2 & 0.004 & 0.023 \pm 0.000 & 0.018 \pm 0.000 & 0.35 \pm 0.00 \\ 3 & 0.006 & 0.036 \pm 0.000 & 0.007 \pm 0.000 & 1.96 \pm 0.00 \\ 4 & 0.008 & 0.057 \pm 0.000 & 0.047 \pm 0.000 & 0.70 \pm 0.00 \\ 5 & 0.010 & 0.052 \pm 0.000 & 0.006 \pm 0.000 & 3.12 \pm 0.00 \\ 6 & 0.012 & 0.064 \pm 0.000 & 0.040 \pm 0.000 & 1.62 \pm 0.00 \\ 7 & 0.014 & 0.060 \pm 0.000 & 0.020 \pm 0.000 & 2.68 \pm 0.00 \\ 8 & 0.016 & 0.074 \pm 0.000 & 0.030 \pm 0.000 & 2.97 \pm 0.00 \\ 9 & 0.018 & 0.071 \pm 0.000 & 0.039 \pm 0.000 & 2.15 \pm 0.00 \\ 10 & 0.020 & 0.098 \pm 0.000 & 0.033 \pm 0.000 & 4.36 \pm 0.00 \\ 11 & 0.022 & 0.101 \pm 0.000 & 0.062 \pm 0.000 & 2.59 \pm 0.00 \\ 12 & 0.024 & 0.107 \pm 0.000 & 0.015 \pm 0.000 & 6.13 \pm 0.00 \\ 13 & 0.026 & 0.144 \pm 0.000 & 0.089 \pm 0.000 & 3.68 \pm 0.00 \\ 14 & 0.028 & 0.132 \pm 0.000 & 0.022 \pm 0.000 & 7.41 \pm 0.00 \\ 15 & 0.030 & 0.139 \pm 0.000 & 0.057 \pm 0.000 & 5.53 \pm 0.00 \\ 16 & 0.032 & 0.133 \pm 0.000 & 0.033 \pm 0.000 & 6.70 \pm 0.00 \\ 17 & 0.034 & 0.149 \pm 0.000 & 0.035 \pm 0.000 & 7.68 \pm 0.00 \\ 18 & 0.036 & 0.131 \pm 0.000 & 0.035 \pm 0.000 & 6.42 \pm 0.00 \\ 19 & 0.038 & 0.140 \pm 0.000 & 0.021 \pm 0.000 & 7.99 \pm 0.00 \\ 20 & 0.040 & 0.149 \pm 0.000 & 0.059 \pm 0.000 & 5.98 \pm 0.00 \\ 21 & 0.042 & 0.149 \pm 0.000 & 0.015 \pm 0.000 & 9.00 \pm 0.00 \\ 22 & 0.044 & 0.174 \pm 0.000 & 0.070 \pm 0.000 & 6.97 \pm 0.00 \\ 23 & 0.046 & 0.163 \pm 0.000 & 0.032 \pm 0.000 & 8.77 \pm 0.00 \\ 24 & 0.048 & 0.187 \pm 0.000 & 0.059 \pm 0.000 & 8.56 \pm 0.00 \\ 25 & 0.050 & 0.176 \pm 0.000 & 0.048 \pm 0.000 & 8.63 \pm 0.00 \\ 26 & 0.052 & 0.181 \pm 0.000 & 0.023 \pm 0.000 & 10.63 \pm 0.00 \\ 27 & 0.054 & 0.182 \pm 0.000 & 0.066 \pm 0.000 & 7.79 \pm 0.00 \\ 28 & 0.056 & 0.186 \pm 0.000 & 0.018 \pm 0.000 & 11.29 \pm 0.00 \\ 29 & 0.058 & 0.190 \pm 0.000 & 0.070 \pm 0.000 & 8.06 \pm 0.00 \\ 30 & 0.060 & 0.187 \pm 0.000 & 0.021 \pm 0.000 & 11.13 \pm 0.00 \\ 31 & 0.062 & 0.200 \pm 0.000 & 0.061 \pm 0.000 & 9.34 \pm 0.00 \\ 32 & 0.064 & 0.186 \pm 0.000 & 0.039 \pm 0.000 & 9.88 \pm 0.00\end{array}$




\begin{tabular}{|c|c|c|c|c|}
\hline & 66 & \pm 0.000 & \pm 0.000 & .00 \\
\hline 34 & 0.068 & $0.200 \pm 0.000$ & $0.064 \pm 0.000$ & $9.14 \pm 0.00$ \\
\hline & 0.070 & $0.211 \pm 0.000$ & $0.019 \pm 0.000$ & $12.94 \pm 0.00$ \\
\hline & 0.072 & $0.235 \pm 0.000$ & $3 \pm 0.000$ & $10.87 \pm 0.00$ \\
\hline & 0.074 & $.234 \pm 0.000$ & $7 \pm 0.000$ & $15.22 \pm 0.00$ \\
\hline & 0.076 & $0.263 \pm 0.000$ & $0.086 \pm 0.000$ & $11.86 \pm 0.00$ \\
\hline & 0.078 & $0.250 \pm 0.000$ & $2 \pm 0.000$ & $13.96 \pm 0.00$ \\
\hline & 0.080 & $0.286 \pm 0.000$ & .000 & $14.05 \pm$ \\
\hline & 0.082 & $0.276 \pm 0.000$ & $0.069 \pm$ & 13.9 \\
\hline & 0.084 & $0.304 \pm 0.000$ & .000 & $17.41 \pm 0.00$ \\
\hline & 0.086 & $0.298 \pm 0.000$ & .000 & 13.6 \\
\hline & 0.088 & $0.299 \pm 0.000$ & .000 & 0.00 \\
\hline & 0.090 & $0.332 \pm 0.000$ & .000 & $14.75 \pm$ \\
\hline & 0.092 & $0.315 \pm 0.000$ & .000 & $19.72 \pm$ \\
\hline & 0.094 & $0.349 \pm 0.000$ & .000 & 16. \\
\hline & 0.096 & \pm 0.000 & \pm 0.000 & \pm 0.00 \\
\hline ) & 0.098 & $0.354 \pm 0.000$ & \pm 0.000 & \pm 0.00 \\
\hline 50 & 0.100 & $0.348 \pm 0.000$ & .000 & 0.00 \\
\hline & 0.102 & \pm 0.000 & $1 \pm 0.000$ & \pm 0.00 \\
\hline 2 & 0.104 & \pm 0.000 & \pm 0.000 & \pm 0.00 \\
\hline 53 & 0.106 & $0.365 \pm 0.000$ & .000 & 0.00 \\
\hline 54 & 0.108 & .000 & .000 & .00 \\
\hline 55 & 0.110 & $0.368 \pm 0.000$ & \pm 0.000 & \pm 0.00 \\
\hline 56 & 0.112 & .000 & .000 & 0.00 \\
\hline 57 & 0.114 & .000 & .000 & 0.00 \\
\hline 58 & 0.116 & .000 & .000 & 0.00 \\
\hline 59 & 0.118 & 0.000 & .000 & .00 \\
\hline 60 & 0.120 & 0.000 & .000 & 0.00 \\
\hline 61 & 0.122 & \pm 0.000 & .000 & .00 \\
\hline 2 & 0.124 & $0.417 \pm 0.000$ & .000 & 0.00 \\
\hline 63 & 0.126 & $0.456 \pm 0.000$ & .000 & 0.00 \\
\hline 64 & 0.128 & $0.424 \pm 0.000$ & .000 & 0.00 \\
\hline 65 & 0.130 & \pm 0.000 & .000 & 0.00 \\
\hline 66 & 0.132 & \pm 0.000 & .000 & 0.00 \\
\hline 67 & 0.134 & $0.450 \pm 0.000$ & 0.000 & 0.00 \\
\hline 68 & 0.136 & \pm 0.000 & .000 & 0.00 \\
\hline 69 & 0.138 & \pm 0.000 & 0.000 & 0.00 \\
\hline 70 & 0.140 & $0.482 \pm 0.000$ & 0.000 & 0.00 \\
\hline 71 & 0.142 & $0.466 \pm 0.000$ & 0.000 & 0.00 \\
\hline 72 & 0.144 & $0.491 \pm 0.000$ & 0.000 & \pm 0.00 \\
\hline 73 & 0.146 & $0.476 \pm 0.000$ & \pm 0.000 & 0.00 \\
\hline 74 & 0.148 & $0.495 \pm 0.000$ & $0.041 \pm 0.000$ & \pm 0.00 \\
\hline 75 & 0.150 & $0.509 \pm 0.000$ & $0.141 \pm 0.000$ & \pm 0.00 \\
\hline 76 & 0.152 & $0.499 \pm 0.000$ & $0.058 \pm 0.000$ & $29.59 \pm 0.00$ \\
\hline 77 & 0.154 & $0.530 \pm 0.000$ & $0.154 \pm 0.000$ & $25.20 \pm 0.00$ \\
\hline 78 & 0.156 & $0.506 \pm 0.000$ & $0.098 \pm 0.000$ & $27.39 \pm 0.00$ \\
\hline 79 & 0.158 & $0.540 \pm 0.000$ & $0.124 \pm 0.000$ & $27.94 \pm 0.00$ \\
\hline 80 & 0.160 & $0.531 \pm 0.000$ & $0.125 \pm 0.000$ & $27.23 \pm 0.00$ \\
\hline 81 & 0.162 & $0.549 \pm 0.000$ & $0.069 \pm 0.000$ & $32.20 \pm 0.00$ \\
\hline 82 & 0.164 & $0.564 \pm 0.000$ & $0.135 \pm 0.000$ & $28.79 \pm 0.00$ \\
\hline 83 & 0.166 & $0.561 \pm 0.000$ & $0.027 \pm 0.000$ & $35.86 \pm 0.00$ \\
\hline 84 & 0.168 & $0.585 \pm 0.000$ & $0.143 \pm 0.000$ & $29.67 \pm 0.00$ \\
\hline 85 & 0.170 & $0.567 \pm 0.000$ & $0.070 \pm 0.000$ & $33.33 \pm 0.00$ \\
\hline 86 & 0.172 & $0.599 \pm 0.000$ & $0.157 \pm 0.000$ & $29.66 \pm 0.00$ \\
\hline 87 & 0.174 & $0.592 \pm 0.000$ & $0.145 \pm 0.000$ & $29.97 \pm 0.00$ \\
\hline
\end{tabular}




$\begin{array}{lllll}88 & 0.176 & 0.621 \pm 0.000 & 0.117 \pm 0.000 & 33.80 \pm 0.00 \\ 89 & 0.178 & 0.607 \pm 0.000 & 0.162 \pm 0.000 & 29.83 \pm 0.00 \\ 90 & 0.180 & 0.616 \pm 0.000 & 0.049 \pm 0.000 & 38.04 \pm 0.00 \\ 91 & 0.182 & 0.637 \pm 0.000 & 0.164 \pm 0.000 & 31.72 \pm 0.00 \\ 92 & 0.184 & 0.616 \pm 0.000 & 0.038 \pm 0.000 & 38.75 \pm 0.00 \\ 93 & 0.186 & 0.658 \pm 0.000 & 0.146 \pm 0.000 & 34.36 \pm 0.00 \\ 94 & 0.188 & 0.628 \pm 0.000 & 0.083 \pm 0.000 & 36.52 \pm 0.00 \\ 95 & 0.190 & 0.672 \pm 0.000 & 0.122 \pm 0.000 & 36.89 \pm 0.00 \\ 96 & 0.192 & 0.656 \pm 0.000 & 0.178 \pm 0.000 & 32.05 \pm 0.00 \\ 97 & 0.194 & 0.673 \pm 0.000 & 0.100 \pm 0.000 & 38.39 \pm 0.00 \\ 98 & 0.196 & 0.686 \pm 0.000 & 0.213 \pm 0.000 & 31.70 \pm 0.00 \\ 99 & 0.198 & 0.674 \pm 0.000 & 0.048 \pm 0.000 & 42.04 \pm 0.00 \\ 100 & 0.200 & 0.703 \pm 0.000 & 0.166 \pm 0.000 & 36.05 \pm 0.00\end{array}$

\section{Kesimpulan}

Ammonium klorida merupakan senyawa anorganik dengan rumus senyawa $\mathrm{NH}_{4} \mathrm{Cl}$, berupa garam Kristal putih yang sangat mudah larut dalam air. Ammonium klorida digunakan sebagai bahan penyedap pada beberapa jenis liquorice. Ammonium klorida merupakan produk reaksi asam klorida dan ammonia. Sifat-sifat termodinamika yang didapatkan untuk senyawa amonium klorida adalah untuk kapasitas kalor (C) $84,1 \mathrm{~J} \mathrm{~mol}^{-1} \mathrm{~K}^{-1}$, entalphi molar standar 94,56 $\mathrm{J} \mathrm{mol}^{-1} \mathrm{~K}^{-1}$, entalphi pembentukan $-314,43 \mathrm{~kJ} \mathrm{~mol}^{-1}$, dan energi bebas gibs $-202,97 \mathrm{~kJ} \mathrm{~mol}^{-1}$. Pada pengaplikasiannya $\Delta \mathrm{H}$ reaksi yang didapatkan bernilai positif sehingga reaksi pembentukan $\mathrm{NH}_{4} \mathrm{Cl}$ bersifat endotermis. Untuk mengetahui bentuk molekul menggunakan pemodelan komputasi dengan software ChemOffice 15.0. Interaksi molekul yang terjadi pada ion $\mathrm{NH}_{4} \mathrm{Cl}$ dapat diperhatikan melalui beberapa parameter, diantaranya adalah konduktivitas, mobilitas, serta kecepatan hanyut ionnya. Konduktivitas dari $\mathrm{NH}_{4} \mathrm{Cl}$ dipengaruhi oleh konsentrasi, semakin banyak ion yang ada dalam larutan maka mobilitas ion yang juga berhubungan dengan kecepatan hanyut dalam larutan akan semakin berkurang sehingga nilai konduktivitas akan menurun. Mobilitas ion $\mathrm{NH}_{4}^{+}$yaitu $3,5 \times 10^{-8} \mathrm{~m}^{2} \mathrm{~s}^{-1} \mathrm{~V}^{-1}$, serta kecepatan hanyut $\mathrm{NH}_{4} \mathrm{Cl}$ sebesar $3,00 \mathrm{~V} / \mathrm{cm}$. Berdasrkan metoda komputasi dengan ChemOffice 3D, energy yang dibutuhkan $\mathrm{NH}_{4} \mathrm{Cl}$ untuk bergerak sebesar $14,87 \mathrm{kcal} / \mathrm{mol}$.

\section{REFERENSI}

1. nematollahi $\mathrm{Mj}$, Clark Mjr, Ebrahimi P, Ebrahimi M. Preliminary Assessment Of Groundwater Hydrogeochemistry Within Gilan, A Northern Province Of Iran. Environmental Monitoring And Assessment. 2018;190(4):242.

2. Wickramarathna S, Balasooriya S, Diyabalanage S, Chandrajith R. Tracing Environmental Aetiological Factors Of Chronic Kidney Diseases In The Dry Zone Of Sri Lanka-A Hydrogeochemical And Isotope Approach. Journal Of Trace Elements In Medicine And Biology : Organ Of The Society For Minerals And Trace Elements. 2017;44:298-306.

3. Kajthunyakarn W, Sakloetsakun D, Pongjanyakul T. Sodium Caseinate-Magnesium Aluminum Silicate Nanocomposite Films For Modified-Release Tablets. Materials Science \& Engineering C, Materials For Biological Applications. 2018;92:827-39.

4. Huang B, Liu M, Long Z, Shen Y, Zhou C. Effects Of Halloysite Nanotubes On Physical Properties And Cytocompatibility Of Alginate Composite Hydrogels. Materials Science \& Engineering C, Materials For Biological Applications. 2017;70(Pt 1):303-10.

5. Kearney K, Seo G, Matsushima T, Adachi C, Ertekin E, Rockett Aa. Computational Analysis Of The Interplay Between Deep Level Traps And Perovskite Solar Cell Efficiency. Journal Of The American Chemical Society. 2018.

6. Zhang Q, Zhang N, Kang L, Hu G, Yan X, Ding X, Et Al. Technology Development For Simultaneous Wearable Monitoring Of Cerebral Hemodynamics And Blood Pressure. Ieee Journal Of Biomedical And Health Informatics. 2018.

7. Neschen S, Wu M, Fuchs C, Kondofersky I, Theis Fj, De Angelis Mh, Et Al. Impact Of Brain Fatty Acid Signaling On Peripheral Insulin Action In Mice. Experimental And 
Clinical Endocrinology \& Diabetes : Official Journal, German Society Of Endocrinology [And] German Diabetes Association. 2018.

8. Yu Z, Li B, Chu J, Zhang P. Silica In Situ Enhanced Pva/Chitosan Biodegradable Films For Food Packages. Carbohydrate Polymers. 2018;184:214-20.

9. Nalaparaju A, Babarao R, Zhao Xs, Jiang Jw. Atomistic Insight Into Adsorption, Mobility, And Vibration Of Water In Ion-Exchanged Zeolite-Like Metal-Organic Frameworks. Acs Nano. 2009;3(9):2563-72.

10. Liberelle B, Giasson S. Friction And Normal Interaction Forces Between Irreversibly Attached Weakly Charged Polymer Brushes. Langmuir : The Acs Journal Of Surfaces And Colloids. 2008;24(4):1550-9.

11. Heuss Sc, Schwartz Bj, Schneeberger Ar. Second Opinions In Psychiatry: A Review. Journal Of Psychiatric Practice. 2018;24(6):434-42.

12. Qing J, Chen A, Zhao N. Quantifying The Protein-Protein Association Rate In Polymer Solutions: Crowding-Induced Diffusion And Energy Modifications. Physical Chemistry Chemical Physics : Pccp. 2018.

13. Valiei A, Okshevsky M, Lin N, Tufenkji N. Anodized Aluminum With Nanoholes Impregnated With Quaternary Ammonium Compounds Can Kill Pathogenic Bacteria Within Seconds Of Contact. Acs Applied Materials \& Interfaces. 2018.

14. Noje C, Bembea Mm, Nelson Mcmillan Kl, Brunetti Ma, Bernier Ml, Costabile Pm, Et Al. A National Survey On Interhospital Transport Of Children In Cardiac Arrest. Pediatric Critical Care Medicine : A Journal Of The Society Of Critical Care Medicine And The World Federation Of Pediatric Intensive And Critical Care Societies. 2018.

15. Chen J, Jiang H, Li F, Hu B, Wang Y, Wang M, Et Al. Computational Insight Into Dengue Virus Ns2b-Ns3 Protease Inhibition: A Combined Ligand- And Structure-Based Approach. Computational Biology And Chemistry. 2018;77:261-71.

16. Jesionek K, Kostur M. Low-Density Lipoprotein Accumulation Within The Right Coronary Artery Walls For Physiological And Hypertension Conditions. Bio Systems. 2018.

17. Abinaya Sindu P, Kolanthai E, Suganthi Rv, Thanigai Arul K, Manikandan E, Catalani Lh, Et Al. Green Synthesis Of Si-Incorporated Hydroxyapatite Using Sodium Metasilicate As Silicon Precursor And In Vitro Antibiotic Release Studies. Journal Of Photochemistry And Photobiology B, Biology. 2017;175:163-72.

18. Gregg Rw, Sarkar Sn, Shoemaker Je. Mathematical Modeling Of The Cgas Pathway Reveals Robustness Of Dna Sensing To Trex1 Feedback. Journal Of Theoretical Biology. 2018.

19. Li Jk, Kaya M, Kerkhof Plm. Quantitative Cardiology And Computer Modeling Analysis Of Heart Failure In Systole And In Diastole. Computers In Biology And Medicine. 2018;103:252-61.

20. Gopalan G, Prabha B, Joe A, Reshmitha Tr, Sherin Dr, Abraham B, Et Al. Screening Of Musa Balbisiana Colla. Seeds For Antidiabetic Properties And Isolation Of Apiforol, A Potential Lead, With Antidiabetic Activity. Journal Of The Science Of Food And Agriculture. 2018.

21. Gluth S, Spektor Ms, Rieskamp J. Value-Based Attentional Capture Affects MultiAlternative Decision Making. Elife. 2018;7.

22. Gao B, Zhang G, Zhou X, Huang H. Palladium-Catalyzed Regiodivergent Hydroaminocarbonylation Of Alkenes To Primary Amides With Ammonium Chloride. Chemical Science. 2018;9(2):380-6.

23. Ji X, Gao B, Zhou X, Liu Z, Huang H. Palladium-Catalyzed Regioselective Hydroaminocarbonylation Of Alkynes To Alpha,Beta-Unsaturated Primary Amides With Ammonium Chloride. The Journal Of Organic Chemistry. 2018;83(17):10134-41.

24. Jiang W, Wang Yl, Fang Bs. Resolution Mechanism And Characterization Of An Ammonium Chloride-Tolerant, High-Thermostable, And Salt-Tolerant Phenylalanine Dehydrogenase From Bacillus Halodurans. Applied Biochemistry And Biotechnology. 2018.

25. Kim Ji, Son Sk. Stable Antimicrobial Activity Achieved Via Immobilization Of Quaternary Ammonium Chloride On Hair. Biocontrol Science. 2018;23(2):71-6. 
26. Li J, Zhao L, Wu Y, Rajoka Msr. Insights On The Ultra High Antibacterial Activity Of Positionally Substituted 2'-O-Hydroxypropyl Trimethyl Ammonium Chloride Chitosan: A Joint Interaction Of -Nh2 And -N(+)(Ch3)3 With Bacterial Cell Wall. Colloids And Surfaces B, Biointerfaces. 2018;173:429-36.

27. Price Jt, Gao W, Fatehi P. Lignin-G-Poly(Acrylamide)-G-Poly(DiallyldimethylAmmonium Chloride): Synthesis, Characterization And Applications. Chemistryopen. 2018;7(8):645-58.

28. Rezaei B, Jamei Hr, Ensafi Aa. Lysozyme Aptasensor Based On A Glassy Carbon Electrode Modified With A Nanocomposite Consisting Of Multi-Walled Carbon Nanotubes, Poly(Diallyl Dimethyl Ammonium Chloride) And Carbon Quantum Dots. Mikrochimica Acta. 2018;185(3):180.

29. Zach R, Tvaruzkova J, Schatz M, Tupa O, Grallert B, Prevorovsky M. Mitotic Defects In Fission Yeast Lipid Metabolism 'Cut' Mutants Are Suppressed By Ammonium Chloride. Fems Yeast Research. 2018;18(6).

30. Liang J, Wei D, Lin N, Zhu Y, Li X, Zhang J, Et Al. Low Temperature Chemical Reduction Of Fusional Sodium Metasilicate Nonahydrate Into A Honeycomb Porous Silicon Nanostructure. Chemical Communications. 2014;50(52):6856-9.

31. Pyatina T, Sugama T, Moon J, James S. Effect Of Tartaric Acid On Hydration Of A Sodium-Metasilicate-Activated Blend Of Calcium Aluminate Cement And Fly Ash F. Materials. 2016;9(6).

32. Rioland G, Dutournie P, Faye D, Daou Tj, Patarin J. Prediction Of The Mechanical Properties Of Zeolite Pellets For Aerospace Molecular Decontamination Applications. Beilstein Journal Of Nanotechnology. 2016;7:1761-71.

33. Chauhan Ds, Ansari Kr, Sorour Aa, Quraishi Ma, Lgaz H, Salghi R. Thiosemicarbazide And Thiocarbohydrazide Functionalized Chitosan As Ecofriendly Corrosion Inhibitors For Carbon Steel In Hydrochloric Acid Solution. International Journal Of Biological Macromolecules. 2018;107(Pt B):1747-57.

34. Li X, Guo Y, Shen Z. Hydrochloric Acid-Promoted Intermolecular 1,2Thiofunctionalization Of Aromatic Alkenes. The Journal Of Organic Chemistry. 2018;83(5):2818-29.

35. Shakeri Yekta S, Hedenstrom M, Stehr Je, Dario M, Hertkorn N, Bjorn A. Pretreatment Of Anaerobic Digester Samples By Hydrochloric Acid For Solution-State (1)H And (13)C Nmr Spectroscopic Characterization Of Organic Matter. Chemosphere. 2018;199:201-9.

36. Weibel G, Eggenberger U, Kulik Da, Hummel W, Schlumberger S, Klink W, Et Al. Extraction Of Heavy Metals From Mswi Fly Ash Using Hydrochloric Acid And Sodium Chloride Solution. Waste Management. 2018;76:457-71.

37. Xu X, Singh A, Sun Z, Ansari Kr, Lin Y. Theoretical, Thermodynamic And Electrochemical Analysis Of Biotin Drug As An Impending Corrosion Inhibitor For Mild Steel In 15\% Hydrochloric Acid. Royal Society Open Science. 2017;4(12):170933.

38. Liu Y, He C, Tang Y, Imler Gh, Parrish Da, Shreeve Jm. Asymmetric Nitrogen-Rich Energetic Materials Resulting From The Combination Of Tetrazolyl, Dinitromethyl And (1,2,4-Oxadiazol-5-Yl)Nitroamino Groups With Furoxan. Dalton Transactions. 2018.

39. Burdick Rk, Varnavski O, Molina A, Upton L, Zimmerman P, Goodson T, 3rd. Predicting And Controlling Entangled Two-Photon Absorption In Diatomic Molecules. The Journal Of Physical Chemistry A. 2018;122(41):8198-212.

40. Telnov Da, Krapivin Da, Heslar J, Chu Si. Multiphoton Ionization Of One-Electron Relativistic Diatomic Quasimolecules In Strong Laser Fields. The Journal Of Physical Chemistry A. 2018;122(40):8026-36.

41. Chen Q, Zhao Yx, Jiang Lx, Chen Jj, He Sg. Coupling Of Methane And Carbon Dioxide Mediated By Diatomic Copper Boride Cations. Angewandte Chemie. 2018;57(43):14134-8.

42. Geng C, Li J, Weiske T, Schwarz H. Ta2 (+)-Mediated Ammonia Synthesis From N2 And H2 At Ambient Temperature. Proceedings Of The National Academy Of Sciences Of The United States Of America. 2018.

43. Mauksch M, Tsogoeva Sb. Spin-Paired Solvated Electron Couples In Alkali-Ammonia Systems. Physical Chemistry Chemical Physics : Pccp. 2018. 
44. Mouthier Tmb, De Rink B, Van Erven G, De Gijsel P, Schols Ha, Kabel Ma. Low Liquid Ammonia Treatment Of Wheat Straw Increased Enzymatic Cell Wall Polysaccharide Degradability And Decreased Residual Hydroxycinnamic Acids. Bioresource Technology. 2018;272:288-99.

45. Wang Y, Luo W, Cheng W, Hu M, Wang Q, Cheng X, Et Al. Ultrahigh Catalytic Activity Of L-Proline-Functionalized Rh Nanoparticles For Methanolysis Of Ammonia Borane. Chemsuschem. 2018.

46. Xue X, Chen R, Chen H, Hu Y, Ding Q, Liu Z, Et Al. Oxygen Vacancy Engineering Promoted Photocatalytic Ammonia Synthesis On Ultrathin Two-Dimensional Bismuth Oxybromide Nanosheets. Nano Letters. 2018.

47. Reszka Kj, Bilski P, Chignell Cf. Spin Trapping Of Nitric Oxide By Aci Anions Of Nitroalkanes. Nitric Oxide : Biology And Chemistry. 2004;10(2):53-9.

48. Bohnke J, Bruckner T, Hermann A, Gonzalez-Belman Of, Arrowsmith M, Jimenez-Halla Joc, Et Al. Single And Double Activation Of Acetone By Isolobal B[Triple Bond, Length As M-Dash]N And B[Triple Bond, Length As M-Dash]B Triple Bonds. Chemical Science. 2018;9(24):5354-9.

49. Fuchibe K, Oki R, Hatta H, Ichikawa J. Single C-F Bond Activation Of The Cf3 Group With A Lewis Acid: Cf3 -Cyclopropanes As Versatile 4,4-Difluorohomoallylating Agents. Chemistry. 2018.

50. Gerwien A, Schildhauer M, Thumser S, Mayer P, Dube H. Direct Evidence For Hula Twist And Single-Bond Rotation Photoproducts. Nature Communications. 2018;9(1):2510.

51. Huang Is, Tsai Mk. Interplay Between Polarizability And Hydrogen Bond Network Of Water: Reparametrizing The Flexible Single-Point-Charge Water Model By The Nonlinear Adaptive Force Matching Approach. The Journal Of Physical Chemistry A. 2018;122(19):4654-62.

52. Li X, You C, Yang Y, Yang Y, Li P, Gu G, Et Al. Rhodium-Catalyzed Asymmetric Hydrogenation Of Beta-Cyanocinnamic Esters With The Assistance Of A Single Hydrogen Bond In A Precise Position. Chemical Science. 2018;9(7):1919-24.

53. Zhang Y, Huang Z, Wang L, Wang C, Zhang C, Wiese T, Et Al. Point-Of-Care Determination Of Acetaminophen Levels With Multi-Hydrogen Bond Manipulated SingleMolecule Recognition (Emuhsir). Analytical Chemistry. 2018;90(7):4733-40.

54. Berber Mr, Hafez Ih. Synthesis Of A New Nitrate-Fertilizer Form With A Controlled Release Behavior Via An Incorporation Technique Into A Clay Material. Bulletin Of Environmental Contamination And Toxicology. 2018.

55. Boyandin An, Kazantseva Ea, Varygina De, Volova Tg. Constructing Slow-Release Formulations Of Ammonium Nitrate Fertilizer Based On Degradable Poly(3Hydroxybutyrate). Journal Of Agricultural And Food Chemistry. 2017;65(32):6745-52.

56. Castellano Mj, David Mb. Long-Term Fate Of Nitrate Fertilizer In Agricultural Soils Is Not Necessarily Related To Nitrate Leaching From Agricultural Soils. Proceedings Of The National Academy Of Sciences Of The United States Of America. 2014;111(8):E766.

57. Karimi R, Akinremi W. Nitrate Leaching In A Loamy Sand Soil Receiving Two Rates Of Liquid Hog Manure And Fertilizer. Journal Of Environmental Quality. 2018;47(3):513-21.

58. Lentz Rd, Lehrsch Ga. Mineral Fertilizer And Manure Effects On Leached Inorganic Nitrogen, Nitrate Isotopic Composition, Phosphorus, And Dissolved Organic Carbon Under Furrow Irrigation. Journal Of Environmental Quality. 2018;47(2):287-96.

59. Qadir O, Siervo M, Seal Cj, Brandt K. Manipulation Of Contents Of Nitrate, Phenolic Acids, Chlorophylls, And Carotenoids In Lettuce (Lactuca Sativa L.) Via Contrasting Responses To Nitrogen Fertilizer When Grown In A Controlled Environment. Journal Of Agricultural And Food Chemistry. 2017;65(46):10003-10.

60. Quan Z, Huang B, Lu C, Shi Y, Chen X, Zhang H, Et Al. The Fate Of Fertilizer Nitrogen In A High Nitrate Accumulated Agricultural Soil. Scientific Reports. 2016;5:21539.

61. Sebilo M, Mayer B, Nicolardot B, Pinay G, Mariotti A. Reply To Castellano And David: Long-Term Fate Of Nitrate Fertilizer And Nitrate From Agricultural Catchments. Proceedings Of The National Academy Of Sciences Of The United States Of America. 2014;111(8):E767. 
62. Bakaric D, Aleric J, Parlic-Risovic T, Spanget-Larsen J. Hydrogen Bonding Between Ethynyl Aromates And Triethylamine: Ir Spectroscopic And Computational Study. Spectrochimica Acta Part A, Molecular And Biomolecular Spectroscopy. 2018;209:288-94.

63. Gaffney Ka, Hong H. The Rhomboid Protease Glpg Has Weak Interaction Energies In Its Active Site Hydrogen Bond Network. The Journal Of General Physiology. 2018.

64. Gropp C, Husch T, Trapp N, Reiher M, Diederich F. Hydrogen-Bonded Networks: Molecular Recognition Of Cyclic Alcohols In Enantiopure Alleno-Acetylenic Cage Receptors. Angewandte Chemie. 2018.

65. Lai J, Huang B, Chao Y, Chen X, Guo S. Strongly Coupled Nickel-Cobalt Nitrides/Carbon Hybrid Nanocages With Pt-Like Activity For Hydrogen Evolution Catalysis. Advanced Materials. 2018:E1805541.

66. Szczesny J, Markovic N, Conzuelo F, Zacarias S, Pereira Iac, Lubitz W, Et Al. A Gas Breathing Hydrogen/Air Biofuel Cell Comprising A Redox Polymer/Hydrogenase-Based Bioanode. Nature Communications. 2018;9(1):4715.

67. Barba J, Bradford Ma, Brewer Pe, Bruhn D, Covey K, Van Haren J, Et Al. Methane Emissions From Tree Stems: A New Frontier In The Global Carbon Cycle. The New Phytologist. 2018.

68. Dandu Nk, Adeyiga O, Panthi D, Bird Sa, Odoh So. Performance Of Density Functional Theory For Describing Hetero-Metallic Active-Site Motifs For Methane-To-Methanol Conversion In Metal-Exchanged Zeolites. Journal Of Computational Chemistry. 2018.

69. Fu L, Bai Yn, Lu Yz, Ding J, Zhou D, Zeng Rj. Degradation Of Organic Pollutants By Anaerobic Methane-Oxidizing Microorganisms Using Methyl Orange As Example. Journal Of Hazardous Materials. 2018;364:264-71.

70. Nakatani N, Hada M. Can Large Active-Space Casscf Calculation Make Sense To The Reaction Analysis Of Iron Complex? A Benchmark Study Of Methane Oxidation Reaction By Feo(). Journal Of Computational Chemistry. 2018.

71. Nicholson Dp, Michel Apm, Wankel Sd, Manganini K, Sugrue Ra, Sandwith Zo, Et Al. Rapid Mapping Of Dissolved Methane And Carbon Dioxide In Coastal Ecosystems Using The Chemyak Autonomous Surface Vehicle. Environmental Science \& Technology. 2018.

72. Pappas Dk, Martini A, Dyballa M, Kvande K, Teketel S, Lomachenko Ka, Et Al. The Nuclearity Of The Active Site For Methane To Methanol Conversion In Cu-Mordenite: A Quantitative Assessment. Journal Of The American Chemical Society. 2018.

73. Wu X, Lu W, Streacker Lm, Ashbaugh Hs, Ben-Amotz D. Methane Hydration-Shell Structure And Fragility. Angewandte Chemie. 2018;57(46):15133-7.

74. Wang Y, Wu X, Yi J, Chen L, Lan T, Dai J. Pretreatment Of Printing And Dyeing Wastewater By Fe/C Micro-Electrolysis Combined With H2o2 Process. Water Science And Technology : A Journal Of The International Association On Water Pollution Research. 2018;2017(3):707-17.

75. Xiong Z, Lai B, Yang P. Insight Into A Highly Efficient Electrolysis-Ozone Process For N,N-Dimethylacetamide Degradation: Quantitative Analysis Of The Role Of Catalytic Ozonation, Fenton-Like And Peroxone Reactions. Water Research. 2018;140:12-23.

76. Zhang Z. Treatment Of Oilfield Wastewater By Combined Process Of Micro-Electrolysis, Fenton Oxidation And Coagulation. Water Science And Technology : A Journal Of The International Association On Water Pollution Research. 2017;76(11-12):3278-88.

77. Zhu W, Gao Yh, Liao Py, Chen Dy, Sun Nn, Nguyen Thi Pa, Et Al. Comparison Between Porphin, Chlorin And Bacteriochlorin Derivatives For Photodynamic Therapy: Synthesis, Photophysical Properties, And Biological Activity. European Journal Of Medicinal Chemistry. 2018;160:146-56.

78. Choi Kh, Nam Kc, Cho G, Jung Js, Park Bj. Enhanced Photodynamic Anticancer Activities Of Multifunctional Magnetic Nanoparticles $(\mathrm{Fe}(3) \mathrm{O}(4))$ Conjugated With Chlorin E6 And Folic Acid In Prostate And Breast Cancer Cells. Nanomaterials. 2018;8(9).

79. Kalaj M, Carter Kp, Cahill Cl. Utilizing Bifurcated Halogen-Bonding Interactions With The Uranyl Oxo Group In The Assembly Of A Uo2-3-Bromo-5-Iodobenzoic Acid Coordination Polymer. Acta Crystallographica Section B, Structural Science, Crystal Engineering And Materials. 2017;73(Pt 2):234-9. 
80. Li W, Zeng Y, Li X, Sun Z, Meng L. The Competition Of Ycdots, Three Dots, Centeredo And Xcdots, Three Dots, Centeredn Halogen Bonds To Enhance The Group V Sigma-Hole Interaction In The Ncycdots, Three Dots, Centeredo $=\mathrm{Ph} 3$ Cdots, Three Dots, Centeredncx And $\mathrm{O}=\mathrm{Ph} 3$ Cdots, Three Dots, Centeredncxcdots, Three Dots, Centeredncy (X, Y=F, Cl, And Br) Complexes. Journal Of Computational Chemistry. 2015;36(18):1349-58.

81. Marek Ph, Urban M, Madura Id. The Study Of Interactions With A Halogen Atom: Influence Of Nh2 Group Insertion On The Crystal Structures Of Meta-Bromonitrobenzene Derivatives. Acta Crystallographica Section C, Structural Chemistry. 2018;74(Pt 11):150917.

82. Miwa T, Suzuki S, Takai R, Yamamoto R, Inoue Y, Yamamoto A. Retention Behavior Of Halogenated Benzenes On A Stationary Phase Having A 2,4-Dibromophenoxy Group As The Halogen Recognition Functional Group. Analytical Sciences : The International Journal Of The Japan Society For Analytical Chemistry. 2015;31(8):841-5.

83. Zha B, Dong M, Miao X, Miao K, Hu Y, Wu Y, Et Al. Controllable Orientation Of EsterGroup-Induced Intermolecular Halogen Bonding In A 2d Self-Assembly. The Journal Of Physical Chemistry Letters. 2016;7(16):3164-70.

84. Dauletyarov Y, Dixon Ar, Wallace Aa, Sanov A. Electron Affinity And Excited States Of Methylglyoxal. The Journal Of Chemical Physics. 2017;147(1):013934.

85. Gaiduk Ap, Pham Ta, Govoni M, Paesani F, Galli G. Electron Affinity Of Liquid Water. Nature Communications. 2018;9(1):247.

86. Huang X, Yang J. Probing Structure, Thermochemistry, Electron Affinity, And Magnetic Moment Of Thulium-Doped Silicon Clusters Tmsi N (N = 3-10) And Their Anions With Density Functional Theory. Journal Of Molecular Modeling. 2017;24(1):29.

87. James Mc, Croot A, May Pw, Allan Nl. Negative Electron Affinity From Aluminium On The Diamond (1 0 0) Surface: A Theoretical Study. Journal Of Physics Condensed Matter : An Institute Of Physics Journal. 2018;30(23):235002.

88. Wang D, Ivanova Lv, Ivanov Mv, Mirzaei S, Timerghazin Qk, Reid Sa, Et Al. An ElectronRich Calix[4]Arene-Based Receptor With Unprecedented Binding Affinity For Nitric Oxide. Chemistry. 2018.

89. Ziaei V, Bredow T. Probing Ionization Potential, Electron Affinity And Self-Energy Effect On The Spectral Shape And Exciton Binding Energy Of Quantum Liquid Water With SelfConsistent Many-Body Perturbation Theory And The Bethe-Salpeter Equation. Journal Of Physics Condensed Matter : An Institute Of Physics Journal. 2018;30(21):215502.

90. Chilakala S, Cheng I, Lee I, Xu Y. Analysis Of Oxygen-18 Labeled Phosphate To Study Positional Isotope Experiments Using Lc-Qtof-Ms. Analytical Biochemistry. 2018.

91. Epel B, Maggio Mc, Barth Ed, Miller Rc, Pelizzari Ca, Krzykawska-Serda M, Et Al. Oxygen-Guided Radiation Therapy. International Journal Of Radiation Oncology, Biology, Physics. 2018.

92. Gao Wk, Chi Jq, Wang Zb, Lin Jh, Liu Dp, Zeng Jb, Et Al. Optimized Bimetallic NickelIron Phosphides With Rich Defects As Enhanced Electrocatalysts For Oxygen Evolution Reaction. Journal Of Colloid And Interface Science. 2018;537:11-9.

93. Gil Hn, Jung E, Koh D, Lim Y, Lee Yh, Shin Sy. A Synthetic Chalcone Derivative, 2Hydroxy-3',5,5'-Trimethoxychalcone (Dk-139), Triggers Reactive Oxygen Species-Induced Apoptosis Independently Of P53 In A549 Lung Cancer Cells. Chemico-Biological Interactions. 2018.

94. Lampp L, Rogozhnikova Oy, Trukhin Dv, Tormyshev Vm, Bowman Mk, Devasahayam N, Et Al. A Radical Containing Injectable In-Situ-Oleogel And Emulgel For Prolonged InVivo Oxygen Measurements With Cw Epr. Free Radical Biology \& Medicine. 2018;130:120-7.

95. Partanen L, Murdachaew G, Laasonen K. Oxygen Evolution Reaction Kinetic Barriers On Nitrogen-Doped Carbon Nanotubes. The Journal Of Physical Chemistry C, Nanomaterials And Interfaces. 2018;122(24):12892-9.

96. Tao H, Bobaker Am, Ramal Mm, Yaseen Zm, Hossain Ms, Shahid S. Determination Of Biochemical Oxygen Demand And Dissolved Oxygen For Semi-Arid River Environment: 
Application Of Soft Computing Models. Environmental Science And Pollution Research International. 2018.

97. Yang L, Zhang B, Fang B, Feng L. A Comparative Study Of Nico2o4 Catalyst Supported On Ni Foam And From Solution Residuals Fabricated By A Hydrothermal Approach For Electrochemical Oxygen Evolution Reaction. Chemical Communications. 2018.

98. Bartyzel J, Rozanski K. Dating Of Young Groundwater Using Four Anthropogenic Trace Gases (Sf6, Sf5cf3, Cfc-12 And Halon-1301): Methodology And First Results. Isotopes In Environmental And Health Studies. 2016;52(4-5):393-404.

99. Bauza A, Frontera A. Theoretical Study On Sigma- And Pi-Hole Carboncarbon Bonding Interactions: Implications In Cfc Chemistry. Physical Chemistry Chemical Physics : Pccp. 2016;18(47):32155-9.

100. Hand E. Atmospheric Science. Cfc Bans Pay Off As Antarctic Ozone Layer Starts To Mend. Science. 2016;353(6294):16-7.

101. Montzka Sa, Dutton Gs, Yu P, Ray E, Portmann Rw, Daniel Js, Et Al. An Unexpected And Persistent Increase In Global Emissions Of Ozone-Depleting Cfc-11. Nature. 2018;557(7705):413-7.

102. Wen C, Lim Cs, Ye A, Zhu Jj. Erratum: Single-Molecule Force Measurement Via Optical Tweezers Reveals Different Kinetic Features Of Two Braf Mutants Responsible For Cardio-Facial-Cutaneous (Cfc) Syndrome: Errata. Biomedical Optics Express. 2015;6(1):244.

103. Zavras N, Poddighe D. Cranial Fasciitis Of Childhood (Cfc): An Unusual Clinical Case Of A Rare Disease. Bmj Case Reports. 2017;2017.

104. Hoegg Ed, Manard Bt, Wylie Em, Mathew Kj, Ottenfeld Cf, Marcus Rk. Initial Benchmarking Of The Liquid Sampling-Atmospheric Pressure Glow Discharge-Orbitrap System Against Traditional Atomic Mass Spectrometry Techniques For Nuclear Applications. Journal Of The American Society For Mass Spectrometry. 2018.

105. Schwob L, Lalande M, Chesnel Jy, Domaracka A, Huber Ba, Maclot S, Et Al. A Tandem Mass Spectrometer For Crossed-Beam Irradiation Of Mass-Selected Molecular Systems By Kev Atomic Ions. The Review Of Scientific Instruments. 2018;89(4):043104.

106. Han G, Chen Sy, Gonzalez Vd, Zunder Er, Fantl Wj, Nolan Gp. Atomic Mass Tag Of Bismuth-209 For Increasing The Immunoassay Multiplexing Capacity Of Mass Cytometry. Cytometry Part A : The Journal Of The International Society For Analytical Cytology. 2017;91(12):1150-63.

107. Gallego A, Sezer U, Arndt M, Mayor M. Long-Pulse Laser Launch And Ionization Of Tailored Large Neutral Silver Nanoparticles With Atomic Mass Assignment. Nanoscale. 2017;9(26):9175-80.

108. Liu Y, Li X, Qi J, Zhang N, Xia C. The Structural Basis Of Chicken, Swine And Bovine Cd8alphaalpha Dimers Provides Insight Into The Co-Evolution With Mhc I In Endotherm Species. Scientific Reports. 2016;6:24788.

109. Mizuno M, Pikal Mj. Is The Pre-Tg Dsc Endotherm Observed With Solid State Proteins Associated With The Protein Internal Dynamics? Investigation Of Bovine Serum Albumin By Solid State Hydrogen/Deuterium Exchange. European Journal Of Pharmaceutics And Biopharmaceutics : Official Journal Of Arbeitsgemeinschaft Fur Pharmazeutische Verfahrenstechnik Ev. 2013;85(2):170-6.

110. Dai Y, Dabrowski M, Apkarian Va, Petek H. Ultrafast Microscopy Of Spin-MomentumLocked Surface Plasmon Polaritons. Acs Nano. 2018;12(7):6588-96.

111. Hage Fs, Nicholls Rj, Yates Jr, Mcculloch Dg, Lovejoy Tc, Dellby N, Et Al. Nanoscale Momentum-Resolved Vibrational Spectroscopy. Science Advances. 2018;4(6):Eaar7495.

112. Mineo H, Kim Gs, Lin Sh, Fujimura Y. Quantum Design For Ultrafast Probing Of Molecular Chirality Through Enantiomer-Specific Coherent Pi-Electron Angular Momentum. The Journal Of Physical Chemistry Letters. 2018;9(18):5521-6.

113. Nam Ms, Williams Bh, Chen Y, Contera S, Yao S, Lu M, Et Al. Author Correction: How To Probe The Spin Contribution To Momentum Relaxation In Topological Insulators. Nature Communications. 2018;9(1):729. 
114. Nemsak S, Gehlmann M, Kuo Ct, Lin Sc, Schlueter C, Mlynczak E, Et Al. Element- And Momentum-Resolved Electronic Structure Of The Dilute Magnetic Semiconductor Manganese Doped Gallium Arsenide. Nature Communications. 2018;9(1):3306.

115. Achuthan $\mathrm{S}$, Chung Bj, Ghosh $\mathrm{P}$, Rangachari V, Vaidya A. A Modified Stokes-Einstein Equation For Abeta Aggregation. Bmc Bioinformatics. 2011;12 Suppl 10:S13.

116. Hickey Aj, Edwards Da. Density And Shape Factor Terms In Stokes' Equation For Aerodynamic Behavior Of Aerosols. Journal Of Pharmaceutical Sciences. 2018;107(3):7946.

117. Otevrel M, Kleparnik K. Electroosmotic Flow In Capillary Channels Filled With Nonconstant Viscosity Electrolytes: Exact Solution Of The Navier-Stokes Equation. Electrophoresis. 2002;23(20):3574-82.

118. Rajian Jr, Quitevis El. Translational Diffusion In Sucrose Benzoate Near The Glass Transition: Probe Size Dependence In The Breakdown Of The Stokes-Einstein Equation. The Journal Of Chemical Physics. 2007;126(22):224506.

119. Cho J, Waetzig Gr, Udayakantha M, Hong Cy, Banerjee S. Incorporation Of Hydroxyethylcellulose-Functionalized Halloysite As A Means Of Decreasing The Thermal Conductivity Of Oilwell Cement. Scientific Reports. 2018;8(1):16149.

120. Hsieh Pl, Lee At, Chen Lj, Huang Mh. Germanium Wafers Possess Facet-Dependent Electrical Conductivity Properties. Angewandte Chemie. 2018.

121. Kaklamani G, Kazaryan D, Bowen J, Iacovella F, Anastasiadis Sh, Deligeorgis G. On The Electrical Conductivity Of Alginate Hydrogels. Regenerative Biomaterials. 2018;5(5):293301.

122. Pandey J, Shrivastava V, Nagarajan R. Metastable Bi2zr2o7 With Pyrochlore-Like Structure: Stabilization, Oxygen Ion Conductivity, And Catalytic Properties. Inorganic Chemistry. 2018.

123. Reczynski M, Nowicka B, Nather C, Koziel M, Nakabayashi K, Ohkoshi Si, Et Al. Dehydration-Triggered Charge Transfer And High Proton Conductivity In $(\mathrm{H} 3 \mathrm{o})[\mathrm{Ni}(\mathrm{Iii})(\mathrm{Cyclam})][\mathrm{M}(\mathrm{Ii})(\mathrm{Cn}) 6](\mathrm{M}=\mathrm{Ru}, \mathrm{Os})$ Cyanide-Bridged Chains. Inorganic Chemistry. 2018.

124. Yu F, Kurmoo M, Zhuang Gl, Zuo Jl. Hierarchical Tandem Assembly Of Planar [3x3] Building Units Into $\{3 \times[3 \times 3]\}$ Oligomers: Mixed-Valency, Electrical Conductivity And Magnetism. Chemical Science. 2018;9(38):7498-504.

125. Yuan D, Liu L, Jiao X, Zou Y, Mcneill Cr, Xu W, Et Al. Quinoid-Resonant Conducting Polymers Achieve High Electrical Conductivity Over 4000 S Cm(-1) For Thermoelectrics. Advanced Science. 2018;5(10):1800947.

126. Zhan N, Chen B, Li C, Shen Pk. Molecular Dynamics Simulations Of The Thermal Conductivity Of Graphene For Application In Wearable Devices. Nanotechnology. 2018;30(2):025705.

127. Zhang D, Oliynyk Ao, Duarte Gm, Iyer Ak, Ghadbeigi L, Kauwe Sk, Et Al. Not Just Par For The Course: 73 Quaternary Germanides Re4 M2 Xge4 ( Re = La-Nd, Sm, Gd-Tm, Lu; $\mathrm{M}=\mathrm{Mn}-\mathrm{Ni} ; \mathrm{X}=\mathrm{Ag}, \mathrm{Cd}$ ) And The Search For Intermetallics With Low Thermal Conductivity. Inorganic Chemistry. 2018.

128. Bolinsson H, Lu Y, Hall S, Nilsson L, Hakansson A. An Alternative Method For Calibration Of Flow Field Flow Fractionation Channels For Hydrodynamic Radius Determination: The Nanoemulsion Method (Featuring Multi Angle Light Scattering). Journal Of Chromatography A. 2018;1533:155-63.

129. Nygaard M, Kragelund Bb, Papaleo E, Lindorff-Larsen K. An Efficient Method For Estimating The Hydrodynamic Radius Of Disordered Protein Conformations. Biophysical Journal. 2017;113(3):550-7.

130. Shen C, Zhou Q, Zhao M, Lu X, Song P. Photoinduced Electron Transfer In Conjugated Molecules Containing Different Donor In An External Electric Field. Spectrochimica Acta Part A, Molecular And Biomolecular Spectroscopy. 2019;208:294-8.

131. Dorsey Bm, Cass Cl, Cedeno Dl, Vallejo R, Jones Ma. Effects Of Specific Electric Field Stimulation On The Release And Activity Of Secreted Acid Phosphatases From Leishmania Tarentolae And Implications For Therapy. Pathogens. 2018;7(4). 
132. Merkel K, Kocot A, Vij Jk, Shanker G. Distortions In Structures Of The Twist Bend Nematic Phase Of A Bent-Core Liquid Crystal By The Electric Field. Physical Review E. 2018;98(2-1):022704.

133. Ishikawa R, Findlay Sd, Seki T, Sanchez-Santolino G, Kohno Y, Ikuhara Y, Et Al. Direct Electric Field Imaging Of Graphene Defects. Nature Communications. 2018;9(1):3878.

134. Dudev T, Ilieva S, Doudeva L. How An Electric Field Can Modulate The Metal Ion Selectivity Of Protein Binding Sites: Insights From Dft/Pcm Calculations. Physical Chemistry Chemical Physics : Pccp. 2018;20(38):24633-40.

135. Hachtel Ja, Idrobo Jc, Chi M. Sub-Angstrom Electric Field Measurements On A Universal Detector In A Scanning Transmission Electron Microscope. Advanced Structural And Chemical Imaging. 2018;4(1):10.

136. 136. Tucek J, Slouka Z, Pribyl M. Electric Field Assisted Transport Of Dielectric Droplets Dispersed In Aqueous Solutions Of Ionic Surfactants. Electrophoresis. 2018.

137. Dugger Jw, Li W, Chen M, Long Te, Welbourn Rjl, Skoda Mwa, Et Al. Nanoscale Resolution Of Electric-Field Induced Motion In Ionic Diblock Copolymer Thin Films. Acs Applied Materials \& Interfaces. 2018;10(38):32678-87.

138. Mani T, Grills Dc. Nitrile Vibration Reports Induced Electric Field And Delocalization Of Electron In The Charge-Transfer State Of Aryl Nitriles. The Journal Of Physical Chemistry A. 2018;122(37):7293-300.

139. Lee M, Jo Jw, Kim Yj, Choi S, Kwon Sm, Jeon Sp, Et Al. Corrugated Heterojunction Metal-Oxide Thin-Film Transistors With High Electron Mobility Via Vertical Interface Manipulation. Advanced Materials. 2018:E1804120.

140. Zhu R, Li Qs, Li Zs. Nitrogen Substitution Improves The Mobility And Stability Of Electron Transport Materials For Inverted Perovskite Solar Cells. Nanoscale. 2018;10(37):17873-83.

141. Ahmed Mf, Alam L, Mohamed Car, Mokhtar Mb, Ta Gc. Health Risk Of Polonium 210 Ingestion Via Drinking Water: An Experience Of Malaysia. International Journal Of Environmental Research And Public Health. 2018;15(10).

142. El-Tabba Rm, Mathew P, Masocha W, Khajah Ma. Col3 Enhances The Antiproliferative And Proapoptotic Effects Of Paclitaxel In Breast Cancer Cells. Oncology Reports. 2018.

143. Joseph A, Khoshkenar A, Taaffe Km, Catchpole K, Machry H, Bayramzadeh S, Et Al. Minor Flow Disruptions, Traffic-Related Factors And Their Effect On Major Flow Disruptions In The Operating Room. Bmj Quality \& Safety. 2018.

144. Monzio Compagnoni G, Kleiner G, Samarani M, Aureli M, Faustini G, Bellucci A, Et Al. Mitochondrial Dysregulation And Impaired Autophagy In Ipsc-Derived Dopaminergic Neurons Of Multiple System Atrophy. Stem Cell Reports. 2018.

145. Rubio Rr, Gandhi S, Benet A, Tabani H, Burkhardt Jk, Kola O, Et Al. Internal Maxillary Artery To Anterior Circulation Bypass With Local Interposition Grafts Using A Minimally Invasive Approach: Surgical Anatomy And Technical Feasibility. World Neurosurgery. 2018.

146. Shirshahi V, Tabatabaei Sn, Hatamie S, Saber R. Functionalized Reduced Graphene Oxide As A Lateral Flow Immuneassay Label For One-Step Detection Of Escherichia Coli O157:H7. Journal Of Pharmaceutical And Biomedical Analysis. 2018;164:104-11.

147. Toyserkani Nm, Jensen Ch, Tabatabaeifar S, Jorgensen Mg, Hvidsten S, Simonsen Ja, Et Al. Adipose-Derived Regenerative Cells And Fat Grafting For Treating Breast CancerRelated Lymphedema: Lymphoscintigraphic Evaluation With 1 Year Of Follow-Up. Journal Of Plastic, Reconstructive \& Aesthetic Surgery : Jpras. 2018.

148. Yermokhin Mv, Sushchik Nn, Tabachishin Vg, Kalacheva Gs, Kolmakova Aa, Gladyshev Mi. Amphibia As A Vector Of Transfer Of Long-Chain Polyunsaturated Omega-3 Fatty Acids From Aquatic To Terrestrial Ecosystems. Doklady Biochemistry And Biophysics. 2018;481(1):195-7.

149. Zainul R. Determination Of The Half-Life And The Quantum Yield Of Zno Semiconductor Photocatalyst In Humic Acid. 2016.

150. Zainul R, Oktavia B, Dewata I. Studi Dinamika Molekular Dan Kinetika Reaksi Pada Pembelahan Molekul Air Untuk Produksi Gas Hidrogen. 2017. 
151. Mawardi M, Deyundha D, Zainul R, Editors. Characterization Of Pcc Cement By Addition Of Napa Soil From Subdistrict Sarilamak 50 Kota District As Alternative Additional Material For Semen Padang. Iop Conference Series: Materials Science And Engineering; 2018: Iop Publishing.

152. Anhar A, Sumarmin R, Zainul R. Measurement Of Glycemic Index Of West Sumatera Local Rice Genotypes For Healthy Food Selection. 2016.

153. Parastar F, Hejazi Sm, Sheikhzadeh M, Alirezazadeh A. A Parametric Study On Hydraulic Conductivity And Self-Healing Properties Of Geotextile Clay Liners Used In Landfills. Journal Of Environmental Management. 2017;202(Pt 1):29-37.

154. Zhu J, Tang C, Zhuang Z, Shi C, Li N, Zhou L, Et Al. Porous And Low-Crystalline Manganese Silicate Hollow Spheres Wired By Graphene Oxide For High-Performance Lithium And Sodium Storage. Acs Applied Materials \& Interfaces. 2017;9(29):24584-90.

155. Mawardi Anwar E, Kosela S, Wibowo W, Zainul R. Study Of Pb (Ii) Biosorption From Aqueous Solution Using Immobilized Spirogyra Subsalsa Biomass. Journal Of Chemical And Pharmaceutical Research. 2015;7:715-22.

156. Desy Kurniawati I, Harmiwati Ss, Chaidir Z, Munaf E. Rahmiana Zein, Hermansyah Aziz, Rahadian Zainul. 2015. Biosorption Of Pb (Ii) From Aqueous Solutions Using Column Method By Lengkeng (Euphoria Logan Lour) Seed And Shell. Journal Of Chemical And Pharmaceutical Research.7:872-7.

157. Zainul R. Effect Of Temperature And Particle Motion Against The Ability Of Zno Semiconductor Photocatalyst In Humic Acid. 2016.

158. Putri Df, Ritonga Hm, Murdiati V, Zainul R. A Review What Is Hydrothermal? 2018.

159. Yolla A, Zainul R. A Review Grinding: Teknik Dan Prinsip Dasar Pada Pengolahan Material.

160. Derbenev In, Filippov Av, Stace Aj, Besley E. Electrostatic Interactions Between Charged Dielectric Particles In An Electrolyte Solution: Constant Potential Boundary Conditions. Soft Matter. 2018;14(26):5480-7.

161. Jiao Y, Adams Bw, Dohn Ao, Moller Kb, Jonsson H, Rose-Petruck C. Ultrafast X-Ray Absorption Study Of Longitudinal-Transverse Phonon Coupling In Electrolyte Aqueous Solution. Physical Chemistry Chemical Physics : Pccp. 2017;19(40):27266-74.

162. Kasahara K, Nakano H, Sato H. Theoretical Study Of The Solvation Effect On The Reductive Reaction Of Vinylene Carbonate In The Electrolyte Solution Of Lithium Ion Batteries. The Journal Of Physical Chemistry B. 2017;121(20):5293-9.

163. Lin D, Cai P, Peacock Cl, Wu Y, Gao C, Peng W, Et Al. Towards A Better Understanding Of The Aggregation Mechanisms Of Iron (Hydr)Oxide Nanoparticles Interacting With Extracellular Polymeric Substances: Role Of Ph And Electrolyte Solution. The Science Of The Total Environment. 2018;645:372-9.

164. Ohshima H. Interaction Between Two Parallel Plates Covered With A Polyelectrolyte Brush Layer In An Electrolyte Solution. Journal Of Biomaterials Science Polymer Edition. 2017;28(10-12):913-24.

165. Salitra G, Markevich E, Afri M, Talyosef Y, Hartmann P, Kulisch J, Et Al. HighPerformance Cells Containing Lithium Metal Anodes, Lini0.6co0.2mn0.2o2 (Ncm 622) Cathodes, And Fluoroethylene Carbonate-Based Electrolyte Solution With Practical Loading. Acs Applied Materials \& Interfaces. 2018;10(23):19773-82.

166. See Ka, Liu Ym, Ha Y, Barile Cj, Gewirth Aa. Effect Of Concentration On The Electrochemistry And Speciation Of The Magnesium Aluminum Chloride Complex Electrolyte Solution. Acs Applied Materials \& Interfaces. 2017;9(41):35729-39.

167. Xu H, Thomas Rk, Penfold J, Li Px, Ma K, Welbourne Rjl, Et Al. The Impact Of Electrolyte On The Adsorption Of The Anionic Surfactant Methyl Ester Sulfonate At The Air-Solution Interface: Surface Multilayer Formation. Journal Of Colloid And Interface Science. 2018;512:231-8.

168. Zhang Q, Leonardi F, Casalini S, Temino I, Mas-Torrent M. High Performing SolutionCoated Electrolyte-Gated Organic Field-Effect Transistors For Aqueous Media Operation. Scientific Reports. 2016;6:39623. 
169. Yasthopi A. Photoelectrosplitting Water For Hydrogen Production Using Illumination Of Indoor Lights. Journal Of Chemical And Pharmaceutical Research. 2015;7(9s):246-56.

170. Zainul R. Disain Dan Modifikasi Kolektor Dan Reflektor Cahaya Pada Panel Sel Surya $\mathrm{Al} / \mathrm{Cu} 2 \mathrm{o}-\mathrm{Gel} \mathrm{Na} 2 \mathrm{so} 4.2015$.

171. Janasch M, Asplund-Samuelsson J, Steuer R, Hudson Ep. Kinetic Modeling Of The Calvin Cycle Identifies Flux Control And Stable Metabolomes In Synechocystis Carbon Fixation. Journal Of Experimental Botany. 2018.

172. Li Q, Deng W, Li C, Sun Q, Huang F, Zhao Y, Et Al. High-Flux Oil/Water Separation With Interfacial Capillary Effect In Switchable Superwetting $\mathrm{Cu}(\mathrm{Oh}) 2 @ Z i f-8$ Nanowire Membranes. Acs Applied Materials \& Interfaces. 2018.

173. Lloyd Cem, Johnes Pj, Freer Je, Carswell Am, Jones Ji, Stirling Mw, Et Al. Determining The Sources Of Nutrient Flux To Water In Headwater Catchments: Examining The Speciation Balance To Inform The Targeting Of Mitigation Measures. The Science Of The Total Environment. 2019;648:1179-200.

174. Mcgilvray Wd, Klein D, Wooten H, Dawson Ja, Hewitt D, Rakhshandeh Ar, Et Al. Immune System Stimulation Induced By Escherichia Coli Lipopolysaccharide Alters Plasma Free Amino Acid Flux And Dietary Nitrogen Utilization In Growing Pigs. Journal Of Animal Science. 2018.

175. Turner Gw, Parrish An, Zager Jj, Fischedick Jt, Lange Bm. Assessment Of Flux Through Oleoresin Biosynthesis In Epithelial Cells Of Loblolly Pine Resin Ducts. Journal Of Experimental Botany. 2018.

176. Febriani, S. S., Yolanda, T., Arianti, V. A., \& Zainul, R. 2018. A Review Solid Stated : Principles And Methode. Https://Doi.Org/10.31227/Osf.Io/7us4x

177. Liza, Y. M., Yasin, R. C., Maidani, S. S., \& Zainul, R. 2018. Sol Gel : Principle And Technique (A Review). Https://Doi.Org/10.31227/Osf.Io/2cuh8

178. Zainul, R. 2016. Effect Of Temperature And Particle Motion Against The Ability Of Zno Semiconductor Photocatalyst In Humic Acid. Https://Doi.Org/10.31227/Osf.Io/Wnygb

179. Dinata, A. A., Rosyadi, A. M., Hamid, S., \& Zainul, R. 2018. A Review Chemical Vapor Deposition : Process And Application. Https://Doi.Org/10.31227/Osf.Io/Yfeau

180. Putri, D. F., Ritonga, H. M., Murdiati, V., \& Zainul, R. 2018. A Review What Is Hydrothermal ?. Https://Doi.Org/10.31227/Osf.Io/Dm56c

181. Awalliyah, A., Ikhwan, H., Nugiasari, V., \& Zainul, R. 2018. A Review Prinsip Dasar Milling Dalam Sintesis Material. Https://Doi.Org/10.31227/Osf.Io/9xsqe

182. Candani, D., Ulfah, M., Noviana, W., \& Zainul, R. 2018. A Review Pemanfaatan Teknologi Sonikasi. Https://Doi.Org/10.31227/Osf.Io/Uxknv

183. Fatimah, P., Jumalia, R., Novianti, E. R., \& Zainul, R. 2018. A Review Teknik Blended: Prinsip Dan Dasar-Dasar. Https://Doi.Org/10.31227/Osf.Io/Tm2w4

184. Zainul, R., Oktavia, B., Dewata, I., \& Efendi, J. 2017. Studi Dinamika Molekular Dan Kinetika Reaksi Pada Pembelahan Molekul Air Untuk Produksi Gas Hidrogen. Https://Doi.Org/10.31227/Osf.Io/876s3

185. Zainul, R., Alif, A., Aziz, H., Arief, S., \& S. 2015. Photoelectrosplitting Water Mechanism At Carbon Electrode Surface Using Indoor Lights. Https://Doi.Org/10.31227/Osf.Io/Vcxq8

186. M., Yani, S. R., \& Zainul, R. (2017, September 4). Aktivasi Tanah Napa Dan Pengaruhnya Terhadap Adsorpsi Ion Timbal (Ii)/ Pb2+. Https://Doi.Org/10.31227/Osf.Io/Ps523

187. P, O. M., A, L. G., S, A. Y. M., \& Zainul, R. (2018, September 1). A Review Grinding : Teknik Dan Prinsip Dasar Pada Pengolahan Material. Https://Doi.Org/10.31227/Osf.Io/Trv4q

188. H., Sanjaya, H., \& Zainul, R. (2016, August 30). Synthesis And Electrical Properties Of Zno-Ito And Al-Ito Thin Film By Spin Coating Technique Through Sol Gel Process. Https://Doi.Org/10.31227/Osf.Io/Unrt4

189. M., Sanjaya, H., \& Zainul, R. (2015, December 30). Characterization Of Napa Soil And Adsorption Of Pb (Ii) From Aqueous Solutions Using On Column Method. Https://Doi.Org/10.31227/Osf.Io/T8fh9

190. Chaidir, Z., Zainul, R., Nurakhbari, D., \& Salim, M. 2016. Optimization Of Spirulina Platensis Culture For Antioxidant Production. Https://Doi.Org/10.17605/Osf.Io/Fd6e4 
191. Zainul R, Oktavia B, Dewata I, Efendi J. 2018.Thermal And Surface Evaluation On The Process Of Forming A Cu2o/Cuo Semiconductor Photocatalyst On A Thin Copper Plate. Proc. Iop Conference Series: Materials Science And Engineering, 2018, 335:012039: Iop Publishing

192. Zainul R, Alif A, Aziz H, Arief S, Dradjad S, Munaf E. 2015. "Design Of Photovoltaic Cell With Copper Oxide Electrode By Using Indoor Lights". Research Journal Of Pharmaceutical Biological And Chemical Sciences 6:353-61

193. Zainul, R. (2016, December 18). Design And Modification Of Copper Oxide Electrodes For Improving Conversion Coefficient Indoors Lights (Pv-Cell) Photocells. Https://Doi.Org/10.31227/Osf.Io/Pgn84

194. Zainul, R. (2016, December 18). Design And Modification Of Copper Oxide Electrodes For Improving Conversion Coefficient Indoors Lights (Pv-Cell) Photocells. Https://Doi.Org/10.31227/Osf.Io/Pgn84

195. Zainul, R. (2016, September 24). Determination Of The Half-Life And The Quantum Yield Of Zno Semiconductor Photocatalyst In Humic Acid. Https://Doi.Org/10.31227/Osf.Io/E8a9x

196. Febriani, S. S., Yolanda, T., Arianti, V. A., \& Zainul, R. (2018, September 2). A Review Solid Stated : Principles And Methode. Https://Doi.Org/10.31227/Osf.Io/7us4x

197. Liza, Y. M., Yasin, R. C., Maidani, S. S., \& Zainul, R. (2018, September 29). Sol Gel : Principle And Technique (A Review). Https://Doi.Org/10.31227/Osf.Io/2cuh8

198. Zainul, R. (2016, November 19). Effect Of Temperature And Particle Motion Against The Ability Of Zno Semiconductor Photocatalyst In Humic Acid. Https://Doi.Org/10.31227/Osf.Io/Wnygb

199. Dinata, A. A., Rosyadi, A. M., Hamid, S., \& Zainul, R. (2018, August 31). A Review Chemical Vapor Deposition : Process And Application. Https://Doi.Org/10.31227/Osf.Io/Yfeau

200. Putri, D. F., Ritonga, H. M., Murdiati, V., \& Zainul, R. (2018, August 31). A Review What Is Hydrothermal ?. Https://Doi.Org/10.31227/Osf.Io/Dm56c

201. Awalliyah, A., Ikhwan, H., Nugiasari, V., \& Zainul, R. (2018, August 31). A Review Prinsip Dasar Milling Dalam Sintesis Material. Https://Doi.Org/10.31227/Osf.Io/9xsqe

202. Candani, D., Ulfah, M., Noviana, W., \& Zainul, R. (2018, September 1). A Review Pemanfaatan Teknologi Sonikasi. Https://Doi.Org/10.31227/Osf.Io/Uxknv

203. Fatimah, P., Jumalia, R., Novianti, E. R., \& Zainul, R. (2018, August 31). A Review Teknik Blended : Prinsip Dan Dasar-Dasar. Https://Doi.Org/10.31227/Osf.Io/Tm2w4

204. Zainul, R., Oktavia, B., Dewata, I., \& Efendi, J. (2017, February 4). Studi Dinamika Molekular Dan Kinetika Reaksi Pada Pembelahan Molekul Air Untuk Produksi Gas Hidrogen. Https://Doi.Org/10.31227/Osf.Io/876s3

205. Zainul, R., Alif, A., Aziz, H., Arief, S., \& S. (2015, October 22). Photoelectrosplitting Water Mechanism At Carbon Electrode Surface Using Indoor Lights. Https://Doi.Org/10.31227/Osf.Io/Vcxq8

206. Zainul, R., Alif, A., Aziz, H., Arief, S., \& S. (2015, October 22). Photoelectrosplitting Water Mechanism At Carbon Electrode Surface Using Indoor Lights. Https://Doi.Org/10.31227/Osf.Io/Vcxq8

207. M., Yani, S. R., \& Zainul, R. (2017, September 4). Aktivasi Tanah Napa Dan Pengaruhnya Terhadap Adsorpsi Ion Timbal (Ii)/ Pb2+. Https://Doi.Org/10.31227/Osf.Io/Ps523

208. P, O. M., A, L. G., S, A. Y. M., \& Zainul, R. (2018, September 1). A Review Grinding: Teknik Dan Prinsip Dasar Pada Pengolahan Material. Https://Doi.Org/10.31227/Osf.Io/Trv4q

209. H., Sanjaya, H., \& Zainul, R. (2016, August 30). Synthesis And Electrical Properties Of Zno-Ito And Al-Ito Thin Film By Spin Coating Technique Through Sol Gel Process. Https://Doi.Org/10.31227/Osf.Io/Unrt4

210. M., Sanjaya, H., \& Zainul, R. (2015, December 30). Characterization Of Napa Soil And Adsorption $\mathrm{Of} \mathrm{Pb}$ (Ii) From Aqueous Solutions Using On Column Method. Https://Doi.Org/10.31227/Osf.Io/T8fh9 
211. Chaidir, Z., Fadjria, N., A., \& Zainul, R. (2016, December 5). Isolation And Molecular Identification Of Freshwater Microalgae In Maninjau Lake West Sumatera.

Https://Doi.Org/10.31227/Osf.Io/Nbcuf

212. Chaidir, Z., Zainul, R., Nurakhbari, D., \& Salim, M. (2016, September 24). Optimization Of Spirulina Platensis Culture For Antioxidant Production. Https://Doi.Org/10.17605/Osf.Io/Fd6e4

213. Zainul R, Oktavia B, Dewata I, Efendi J. Thermal And Surface Evaluation On The Process Of Forming A Cu2o/Cuo Semiconductor Photocatalyst On A Thin Copper Plate. Proc. Iop Conference Series: Materials Science And Engineering, 2018, 335:012039: Iop Publishing

214. Zainul R, Alif A, Aziz H, Arief S, Dradjad S, Munaf E. 2015. Design Of Photovoltaic Cell With Copper Oxide Electrode By Using Indoor Lights. Research Journal Of Pharmaceutical Biological And Chemical Sciences 6:353-61

215. Mawardi M, Deyundha D, Zainul R. Characterization Of Pcc Cement By Addition Of Napa Soil From Subdistrict Sarilamak 50 Kota District As Alternative Additional Material For Semen Padang. Proc. Iop Conference Series: Materials Science And Engineering, 2018, 335:012034: Iop Publishing

216. Anhar A, Sumarmin R, Zainul R. 2016. Measurement Of Glycemic Index Of West Sumatera Local Rice Genotypes For Healthy Food Selection.

217. Zainul R, Dewata I. 2015. Determination Of Ph-Bod-Cod And Degradation In Batang Arau Watersheds At Padang City.

218. Zainul R, Alif A, Aziz H, Arief S. 2015. Disain Geometri Reaktor Fotosel Cahaya Ruang. Jurnal Riset Kimia 8:131

219. Zainul R, Alif A, Aziz H, Arief S, Darajat S. 2015. Modifikasi Dan Karakteristik Iv Sel Fotovoltaik Cu2o/Cu-Gel Na2so4 Melalui Iluminasi Lampu Neon. Eksakta 2:50

220. Yasthopi A. 2015. Photoelectrosplitting Water For Hydrogen Production Using Illumination Of Indoor Lights. Journal Of Chemical And Pharmaceutical Research 7:24656

221. Zainul R. 2015. Disain Dan Modifikasi Kolektor Dan Reflektor Cahaya Pada Panel Sel Surya Al/Cu2o-Gel Na2so4.

222. Mawardi Anwar E, Kosela S, Wibowo W, Zainul R. 2015. Study Of Pb (Ii) Biosorption From Aqueous Solution Using Immobilized Spirogyra Subsalsa Biomass. Journal Of Chemical And Pharmaceutical Research 7:715-22

223. Desy Kurniawati I, Harmiwati Ss, Chaidir Z, Munaf E. Rahmiana Zein, Hermansyah Aziz, Rahadian Zainul. 2015. Biosorption Of Pb (Ii) From Aqueous Solutions Using Column Method By Lengkeng (Euphoria Logan Lour) Seed And Shell. Journal Of Chemical And Pharmaceutical Research 7:872-7

224. Zainul R, Nurakhbari D, Salim M. Optimization Of Spirulina Platensis Culture For Antioxidant Production.

225. Horiza, H., Azhar, M. And Efendi, J. (2017) "Ekstraksi Dan Karakterisasi Inulin Dari Umbi Dahlia (Dahlia Sp.L) Segar Dan Disimpan”, Eksakta: Berkala Ilmiah Bidang Mipa, 18(01), Pp. 31-39. Doi: Https://Doi.Org/10.24036/Eksakta/Vol18-Iss01/14.

226. Iryani, I., Iswendi, I. And Katrina, I. T. (2017) "Uji Aktivitas Anti Diabetes Mellitus Senyawa Metabolit Sekunder Fraksi Air Dari Beras Ketan Hitam ( Oryza Satival. Var Glutinosa) Pada Mencit Putih", Eksakta: Berkala Ilmiah Bidang Mipa, 18(01), Pp. 54-60. Doi: $\underline{\text { Https://Doi.Org/10.24036/Eksakta/Vol18-Iss01/17. }}$

227. Suryelita, S., Etika, S. B. And Kurnia, N. S. (2017) "Isolasi Dan Karakterisasi Senyawa Steroid Dari Daun Cemara Natal (Cupressus Funebris Endl.)", Eksakta: Berkala Ilmiah Bidang Mipa, 18(01), Pp. 86-94. Doi: Https://Doi.Org/10.24036/Eksakta/Vol18-Iss01/23.

228. Iskandar, I., Horiza, H. And Fauzi, N. (2017) "Efektivitas Bubuk Biji Pepaya (Carica Papaya Linnaeaus) Sebagai Larvasida Alami Terhadap Kematian Larva Aedes Aegypty Tahun 2015", Eksakta: Berkala Ilmiah Bidang Mipa, 18(01), Pp. 12-18. Doi: Https://Doi.Org/10.24036/Eksakta/Vol18-Iss01/12.

229. Ramli, R., Jonuarti, R. And Hartono, A. (2017) "Analisis Struktur Nano Dari Lapisan Tipis Cobalt Ferrite Yang Dipreparasi Dengan Metode Sputtering”, Eksakta: Berkala Ilmiah Bidang Mipa, 18(01), Pp. 46-53. Doi: Https://Doi.Org/10.24036/Eksakta/Vol18-Iss01/16. 
230. Sanjaya, H. (2017) "Degradasi Methylene Blue Menggunakan Katalis Zno-Peg Dengan Metode Fotosonolisis”, Eksakta: Berkala Ilmiah Bidang Mipa, 18(02), Pp. 21-29. Doi: Https://Doi.Org/10.24036/Eksakta/Vol18-Iss02/45.

231. Ningsih, S. K. (2017) "Sintesis Dan Karakterisasi Nanopartikel Zno Doped Cu2+ Melalui Metoda Sol-Gel”, Eksakta: Berkala Ilmiah Bidang Mipa, 18(02), Pp. 39-51. Doi: Https://Doi.Org/10.24036/Eksakta/Vol18-Iss02/51.

232. Saiya, A. (2017) "Analisis Residu Klorpirifos Dalam Sayuran Kubis Dengan Metode Hplc Di Beberapa Pasar Tradisional Di Sulawesi Utara”, Eksakta: Berkala Ilmiah Bidang Mipa, 18(02), Pp. 77-85. Doi: Https://Doi.Org/10.24036/Eksakta/Vol18-Iss02/57.

233. Syafei, N. (2017) "Analisa Fenomena Korosi Pelat Pipa Baja Karbon Api 51-X65 Dalam Larutan 250 Ml Asam Asetat Dan 4750 Ml Aquades Pada Kondisi Gas Co2 Dan H2s Jenuh Pada Suhu Ruang”, Eksakta: Berkala Ilmiah Bidang Mipa, 18(02), Pp. 113-120. Doi: Https://Doi.Org/10.24036/Eksakta/Vol18-Iss02/63.

234. Tutuarima, T. (2017) "Sifat Fisik Dan Kimia Marmalade Jeruk Kalamansi (Citrus Microcarpa) : Kajian Konsentrasi Pektin Dan Sukrosa Physical And Chemical Properties Of Marmalade Citrus Of Calamondin (Citrus Microcarpa) : Study Of Pectin And Sucrose Concentrations", Eksakta: Berkala Ilmiah Bidang Mipa, 18(02), Pp. 164-172. Doi: Https://Doi.Org/10.24036/Eksakta/Vol18-Iss02/73.

235. Ruswandi, R. (2018) "Determination Of Fructose Content Resulted By Inulin Hydrolysis With Dns As Oxidizer”, Eksakta: Berkala Ilmiah Bidang Mipa, 19(1), Pp. 14-23. Doi: Https://Doi.Org/10.24036/Eksakta/Vol19-Iss 1/102.

236. Sanjaya, H. (2018) "Degradasi Metil Violet Menggunakan Katalis Zno-Tio2 Secara Fotosonolisis", Eksakta: Berkala Ilmiah Bidang Mipa, 19(1), Pp. 91-99. Doi: Https://Doi.Org/10.24036/Eksakta/Vol19-Iss 1/131.

237. Hidayani, T. (2018) "Grafting Polipropilena Dengan Maleat Anhidrida Sebagai Pengikat Silang Dengan Inisiator Benzoil Peroksida", Eksakta: Berkala Ilmiah Bidang Mipa, 19(1), Pp. 56-62. Doi: $\underline{\text { Https://Doi.Org/10.24036/Eksakta/Vol19-Iss1/127. }}$

238. Prabowo, H. (2018) "Penyelidikan Kelayakan Kimia Dan Penyebaran Cadangan Pasir Besi Daerah Tiku Kabupaten Agam Untuk Bahan Baku Semen Pada Pt. Semen Padang", Eksakta: Berkala Ilmiah Bidang Mipa, 19(1), Pp. 39-42. Doi: Https://Doi.Org/10.24036/Eksakta/Vol19-Iss 1/121. 